\title{
LA PRIMERA DIVISIÓN POLÍTICO-ADMINISTRATIVA DE CHILE, $1811-1826^{2}$
}

En este trabajo sostenemos que, debido a la Independencia y a la consecuente formación del Estado chileno, el país se vio en la necesidad de recurrir a una nueva división interna del territorio nacional con el objeto de establecer un ordenamiento político y administrativo moderno, acorde al modelo republicano. Sin embargo, la idea de establecer una división político-administrativa moderna fue de carácter foráneo, ya que su origen lo encontramos en la división departamental realizada por Francia en la Revolución de 1789, fenómeno que dio un sustento ideológico republicano e igualitario a la organización del espacio.

Palabras clave: División político-administrativa, provincias, representación nacional, criterio geográfico, organización republicana.

This article argues that because of Chile's independence and its eventual process of State-formation, the country needed to establish a new political-administrative order dividing the national territory according to a republican model. However, this was a foreign idea, because the origins of the model applied in Chile came from France's territorial division into Departments that emerged after the French Revolution of 1789. This event gave an egalitarian and republican ideological support to the space organization.

Key words: Political-administrative division, provinces, national representation, geographical criteria, republican organization

Fecha de recepción: abril 2008

Fecha de aceptación: agosto 2008

La temática que desarrollamos se inserta en un período particular de la historia de Chile, una etapa que presentó una conjunción de procesos históricos que influyeron en la gestación y desarrollo de la primera división político-administrativa

1 Licenciada en Historia, Universidad Finis Terrae.

2 Este artículo es producto del proyecto FONDECYT N ${ }^{\circ} 1051034$, de los investigadores José Ignacio González Leiva y Rafael Sagredo Baeza, "Representación cartográfica, ordenamiento político administrativo republicano, consolidación de la nación y desarrollo en Chile", en el que la autora participó como tesista con la investigación "La primera división política de Chile, 1811-1826". 
nacional ${ }^{3}$. Abarcamos en esta investigación exclusivamente las unidades de mayor jerarquía del período analizado, vale decir, las provincias, entre los años 1811 a 1826. Sin embargo, debemos aclarar que este trabajo se ha abordado en función de las disposiciones oficiales adoptadas por la clase política de comienzos del siglo XIX, para organizar el régimen interior del país. Igualmente, hemos comprendido las divisiones político-administrativas como un proceso histórico, de carácter evolutivo, con rasgos de constante movilidad e interrelación con los más variados acontecimientos y realidades históricas. Las unidades territoriales como las provincias o los departamentos van variando, modificándose de acuerdo a las diversas necesidades que se van definiendo con el paso del tiempo y la evolución de la sociedad.

El objetivo fundamental que nos hemos propuesto consiste en identificar la primera división político-administrativa de Chile como país independiente, y comprender su desarrollo y evolución histórica. Pretendemos comprender y analizar su origen y sus antecedentes más directos. Expondremos cómo se fueron aplicando progresivamente los criterios de división provincial y cómo se fueron incorporando al debate sobre este ordenamiento los conceptos republicanos de igualdad y democracia. Para ello dividimos el proceso en dos etapas claramente definidas para comprender la formación de la primera división provincial chilena. Se fijó el punto de separación entre una y otra en el momento en que la división del espacio chileno cambió su fisonomía tradicional de la Colonia por una nueva, una moderna, racional y republicana. Así, factores locales e influencias foráneas marcaron la evolución de la primera división político-administrativa, tanto en su forma como en sus características.

Con la emancipación del país se presentó una problemática dual: ¿continuidad o cambio? La coyuntura que significó la emancipación del dominio hispánico presentó el desafío de continuar con la división existente o, por el contrario, romper con el pasado histórico y elaborar una división completamente nueva. Si finalmente se optó por esta segunda alternativa, es preciso abordar una serie de cuestiones que van íntimamente relacionadas con ella ¿Cuándo se decidió realizar el cambio del ordenamiento político-administrativo?, ¿cuáles fueron los parámetros en los que se basaron para hacer una nueva división del espacio?, ¿cómo se fueron aplicando dichos parámetros dentro de la discusión política y ciudadana de la época? y, por último, ¿cuáles fueron los factores que influyeron en la configuración de la primera división político-administrativa?

\footnotetext{
3 Aclaramos que reconocemos como la primera división política administrativa de Chile, la organización nacional en ocho provincias que se estableció en agosto de 1826, con la aprobación de las leyes federales. De norte a sur, estas fueron las provincias de Coquimbo, Aconcagua, Santiago, Colchagua, Maule, Concepción, Valdivia y Chiloé. Para que esta división llegara a formarse se requirió de tres años de ardua discusión política y, si consideramos que el primer indicio de cambio con el régimen colonial sucedió en 1811, podemos afirmar que el proceso de conformación de la primera división político-administrativa demoró alrededor de quince años en consolidarse.
} 


\section{EL ORIGEN DE LAS DIVISIONES POLÍTICO-ADMINISTRATIVAS MODERNAS: EL MODELO FRANCÉS}

En el siglo XVIII, diversos autores reflexionaron sobre la organización del territorio francés, concluyendo que era necesaria una nueva división del reino. El objetivo común que manifestaron fue materializar un mayor fraccionamiento del territorio, creando unidades más pequeñas con el fin de administrar mejor el espacio y, así, no perder el poder centralizador del Rey. Preconizaron la importancia del poder central como factor de unidad nacional. Así, mientras más pequeñas fueran las unidades que administrar, mayor el control por parte del poder central. Asimismo, comenzó a plantearse la idea de fraccionar el territorio de Francia obedeciendo a un esquema de regularidad y uniformidad de las nuevas unidades administrativas, ya que las circunscripciones del Antiguo Régimen se presentaban como irregulares, incoherentes y desordenadas debido a la superposición y cruce de divisiones eclesiásticas, judiciales, administrativas y financieras, lo que obstaculizaba una administración racional del territorio ${ }^{4}$.

A partir de la Revolución de 1789, los políticos franceses tuvieron la voluntad de organizar el territorio a partir de la proyección de un espacio idealmente concebido, con fines políticos y de administración pública, de modo que los proyectos de división respondieron a una voluntad de acción política en donde el objeto era el territorio ${ }^{5}$. Sin embargo, esta búsqueda de un espacio administrativo ideal se confrontó con un orden preexistente, histórico y geográfico, por lo cual confluyeron dos problemáticas que, si bien son antagónicas, se intentó complementarlas entre sí para lograr un ordenamiento territorial que se adaptara a un espacio real, natural, caracterizado por las particularidades del medio geográfico.

Con la llegada de la Revolución, se delegó en un comité constitucional la tarea de elaborar una división del espacio francés. Ante aquel acontecimiento histórico, los políticos franceses planearon hacer borrón y cuenta nueva, de manera que había que encontrar una nueva forma de organizar el territorio que fuese conforme al nuevo régimen que se quería constituir. El Comité, inspirado en los trabajos de Sieyes y Thouret, presentó un primer proyecto el 29 de septiembre de 1789, el cual dividía Francia en 81 departamentos geométricamente cuadrados, de 18 leguas por lado, cada uno segmentado en 9 cantones. París conformaría un departamento complementario y la división se efectuaría partiendo de este punto hacia las fronteras ${ }^{6}$. No obstante, aquel proyecto, "célebre por su impávida regularidad"7, fue abandonado de inmediato por el Comité que, rechazando de plano la cuadrícula geométrica, prosiguió la discusión para encontrar una división óptima. Así se llegó, el 26 de

\footnotetext{
4 François Furet y Mona Ozouf, Diccionario de la Revolución francesa, Madrid, Alianza, 1989,

5 Marie-Vic Ozouf-Marignier, La formation des Départements: la représentation du territoire français à la fin du $18^{e}$ siècle, París, Éditions de l'École des Hautes Études en Sciences Sociales, $1992,14$.

Ibid., 39.

Furet y Ozouf, op. cit., 450 .
} 451. 
febrero de 1790, al ordenamiento político-administrativo que dividía a Francia en 83 departamentos ${ }^{8}$.

En el debate se consideraron una serie de elementos acordes a un sistema de gobierno republicano. La Ilustración del siglo XVIII y la Revolución de 1789 constituyeron fenómenos que otorgaron un sustento ideológico al ordenamiento territorial francés, en la medida que este se basó en los principios de igualdad y democracia. Uno de los aspectos en los que se manifestó la importancia de este ideal de igualdad, se encuentra en el principal objetivo de la departamentalización francesa: la abolición de los privilegios provinciales del Antiguo Régimen, ya que la antigua demarcación interna representaba elocuentemente los dominios nobiliarios $^{9}$. El soporte ideológico sobre el cual se apoyó esta herramienta de organización nacional se manifestó de dos formas, que también se observan en el caso chileno: su funcionalidad y los criterios utilizados para delinear las circunscripciones. Estos se exteriorizaron en términos de representación, el primero, y a través de una noción de proporcionalidad de los elementos constitutivos que conforman cada unidad administrativa, el segundo.

El proyecto de Sieyes y Thouret se basó específicamente en la funcionalidad de la organización departamental del espacio francés, hecho que se observa claramente en el nombre del proyecto: Reporte de las bases de representación proporcio$n a l^{10}$. El eje de la idea de igualdad respondió a un ideal de representación nacional, propia de un régimen democrático, contrapuesto al sistema absolutista y dominador del Antiguo Régimen, en el cual el objetivo de la delimitación solo respondía a necesidades directas de administración, careciendo de un postulado ideológico concreto. Había que dividir el espacio creando circunscripciones electorales, pues la organización del territorio constituía una garantía para la representación proporcional e igualitaria de la nación ${ }^{11}$.

En el proyecto francés se presentó la novedad de la división político-administrativa moderna. Se establece aquí la necesidad de una representación doble, que opera en dos direcciones: una forma de representación cívico-electoral, que garantizara la igualdad cívica, y una forma de representación netamente administrativa, que asegura la presencia de la administración central en todo el territorio nacional ${ }^{12}$. Sobre este postulado, "todos querían explícitamente el acercamiento entre administradores y administrados, considerado como una garantía de eficacia"13, de modo que reconocían la presencia efectiva de la administración central en todo el territorio nacional,

8 Mona Ozouf asevera que el reordenamiento del espacio se consiguió en un corto período de tiempo. En sus propias palabras, "el departamento nace de las discusiones de la noche del 4 de agosto, se inaugura el 7 de septiembre de 1789 y queda definitivamente terminado el 26 de febrero de 1790 , cuando los departamentos, sus distritos y sus capitales recibieron límites y nombres", momento en el cual Francia se organizó en 83 departamentos. Ibid., 449.

9 André Burguière y Jacques Revel (directeurs), Histoire de la France. L' espace français, París, Seuil, 1989, 120.

10 Ozouf-Marignier, op. cit., 35.

11 Ibid., 26. Véase además, Burguière y Revel, op. cit., 133.

12 Ozouf-Marignier, op. cit., 36.

13 Furet y Ozouf, op . cit., 454. 
constituyendo un instrumento centralizador. La representación cívico-electoral establecía un elemento descentralizador del poder en la medida que la nueva división implicaba un aumento de las instancias electorales, haciendo que el poder político se viera repartido de manera más homogénea. Pero la problemática que gira en torno a la centralización y descentralización administrativa se manifestó en otro objetivo, que estaba dentro de las pretensiones de los políticos franceses y que el marqués de Argenson sintetizó en "la necesidad de encontrar el equilibrio entre una cierta autonomía de gobierno local y el respeto de la autoridad central"14. Esta finalidad corresponde a una medida de política interior que buscaba conciliar la multiplicidad de intereses locales con los nacionales, de modo que la importancia del poder central radica en su papel como factor de unión nacional ${ }^{15}$.

En una segunda fase, el tema de la representación cedió paso al problema propiamente geográfico de la división del territorio, debido a que las proyecciones ideales se vieron obstaculizadas al confrontarse con el espacio real ${ }^{16}$. En cuanto al proceso de departamentalización francés, Mona Ozouf plantea que "el trabajo de delimitación no se hizo solo con regla y compás, y las consideraciones geográficas tuvieron un peso importante en la decisión final" ${ }^{17}$, presentándose así los criterios de circunscripción político-administrativa, los cuales reflejan una segunda interpretación de la idea de igualdad. Esta, dentro de una esfera más tangible, geográfica, gira en torno a términos de proporcionalidad. Se discute sobre cómo realizar la división o bajo qué parámetros se debía hacer el trazado en el mapa de las nuevas jurisdicciones. En un principio los revolucionarios franceses manifestaron dos aspectos fundamentales que debían considerarse: la superficie de los departamentos y su población. Revelaron en algún momento una inclinación hacia los proyectos geométricos e, incluso, se hizo visible la utopía de los cuadrados iguales, como ya se mencionó ${ }^{18}$. A la simetría entre las unidades administrativas se añade el factor población, ya que algunos, como Mirabeau, buscaban la igualdad en el elemento demográfico pues, afirmó, el verdadero determinante en la división territorial era la densidad poblacional. “QQué son seis leguas sin habitantes?”, declaró ${ }^{19}$. Entre ambos elementos, superficie y demografía, la Asamblea tendió hacia la igualdad de los territorios, pero la complementó con una proporcionalidad de los representantes según la población ${ }^{20}$.

Otro principio que se tomó en cuenta al momento de realizar la división departamental fue que se atendiera a las particularidades del medio geográfico. La aspiración de crear un nuevo ordenamiento político-administrativo no pudo sustraerse de considerar la existencia de un orden precedente, natural, e incluirlo en el trazado del mapa. Este fue un aspecto importante para el Comité francés, sobre todo, en

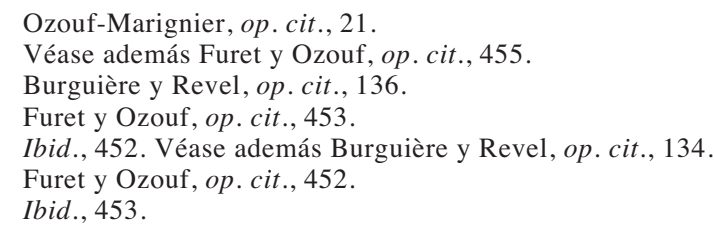


cuestión de límites. "Thouret cita las montañas, los ríos, las ciudades, lo local, la conveniencia económica" como objetos a considerar en la nueva división ${ }^{21}$. Sumado a aquellos, Target incluye "las fronteras de las provincias, la situación de los lugares y la consideración de las costumbres"22. En efecto, ríos, cerros, cordones montañosos e, incluso, islas sirven como fronteras legítimas entre los departamentos, pues son "límites puestos por la mano de la naturaleza"23. Los accidentes geográficos también se vieron como obstáculos naturales en los pedidos de reasignación a otras jurisdicciones por parte de algunos centros poblados, ya que "siempre han tenido una montaña o una rivera infranqueable determinando el rechazo de una reunión a una ciudad capital situada al otro lado del obstáculo", sostiene Ozouf-Marignier ${ }^{24}$.

El origen de la idea de un nuevo ordenamiento político-administrativo en Chile provino del caso francés, pues dicha división departamental proporcionó un modelo moderno de organización del territorio al incorporar en esta los ideales ilustrados de racionalización administrativa, igualdad y democracia, propugnados por la Revolución de 1789. Se añade así un fundamento ideológico implícito a la estructura territorial del país, el cual pretende erigirse como república independiente, democrática y soberana. La división del espacio, por lo tanto, deja de tener el solo objetivo de administración pública, y pasa también a ser políticoadministrativa en la medida que tras de ellas subyace un sistema democrático representativo.

En Chile también se hicieron planteamientos destinados a un mayor fraccionamiento del territorio para lograr la eficiencia administrativa. También se manifestó la idea de la representación nacional a partir del debate suscitado en torno a la creación de las asambleas provinciales y la elección de sus respectivos plenipotenciarios. La cuestión de la igualdad, sin embargo, se expresó en distintas formas y en diversos contextos. El eje de la proporcionalidad entre las circunscripciones se planteó a través de los temas de superficie y población y, más que nada, de los elementos constitutivos de cada unidad político-administrativa. Nos referimos esencialmente a la equidad de los elementos geográficos y económicos que tenía cada provincia para surgir y desarrollarse, la extensión de tierras cultivables y la posesión de boquetes cordilleranos, puertos o vías de comunicación expeditas. Todos ellos apuntaban a que hubiese una igualdad de oportunidades de crecimiento entre las jurisdicciones. Efectivamente, en diversas ocasiones los dirigentes chilenos se refirieron al modelo francés para manifestar la importancia del fraccionamiento del territorio en el desarrollo y adelanto del país. Así, manifestaron en algún momento que "el grado inmenso de prosperidad que a la Francia ha llegado, se atribuye principalmente por los economistas y políticos a la acertada división

21 Ozouf-Marignier, op. cit., 68.

22 Idem.

23 Burguière y Revel, op. cit., 138.

24 Ozouf-Marignier, op. cit., 149.

25 Valentín Letelier, Sesiones de los cuerpos lejislativos de la República de Chile 1811 a 1845, tomo XII, Imprenta Cervantes, Santiago, 1889, sesión del 27 de julio de 1826. (En adelante, SCL). 
territorial que se hizo durante la revolución"25; afirmando que la división del espacio chileno surgió del ejemplo francés, "de donde ciertamente se ha tomado la idea de nuestro proyecto" 26 .

Entre los rasgos más sobresalientes del modelo francés que influyeron en la primera división político-administrativa chilena están también los criterios considerados para realizar el fraccionamiento del territorio, donde resalta la necesidad de adaptar la delimitación provincial a la realidad geográfica. Gracias a la morfología de nuestro territorio, se recurrió principalmente a un criterio de horizontalidad a través del cual debían trazarse líneas divisorias de oriente a poniente, abarcando todo el espacio comprendido entre la cordillera y el mar. El accidente geográfico que más se adecuaba a esta medida eran los ríos, los que además actuaban como un deslinde completamente natural. Si bien se reconoció falta de información respecto de ciertos territorios del Estado, así como un precario conocimiento geográfico, se reconoció que el tema era de trascendental importancia para la elaboración de un fraccionamiento óptimo del espacio chileno.

No sorprende entonces que en el primer esquema que se hizo para un nuevo ordenamiento territorial del país hacia 1823, se hayan establecido departamentos y no provincias. Desde que se inició el quiebre con la tradición colonial, los elementos foráneos se hicieron progresivamente presentes en las discusiones de los cuerpos legislativos de la nación. En un período que se caracterizó por el predominio de los gobiernos locales y la lucha contra el centralismo de Santiago, los patriotas apelaron constantemente a la igualdad de los pueblos y las provincias, resaltando su capacidad de velar por su propio bienestar. Esta idea produjo efectos contraproducentes para la configuración de la primera división políticoadministrativa del país pues, a diferencia del caso francés, el cambio en Chile no fue simultáneo con la transformación del régimen político y demoró un largo tiempo en asentarse.

\section{LA TRADICIÓN COLONIAL}

La primera división político-administrativa de Chile no se presentó como un acontecimiento definido por una fecha determinada, sino como un proceso que estuvo en constante evolución. En una primera etapa, entre 1811 y 1823, esta se caracterizó por ser rudimentaria en diversos puntos, ya que correspondió solo a una enumeración de las provincias existentes, ofreciendo continuidad con la organización administrativa colonial. Planteó la existencia de tres provincias: Coquimbo, en el norte, Santiago, en el centro, y Concepción, en el sur del país. En este período la organización del espacio prácticamente no presentó variación alguna en su composición respecto de la Colonia, pues la jurisdicción territorial de las provincias permaneció inalterable. Por tanto, ubicamos como antecedente directo de la división de 1811, el sistema de intendencias del siglo XVIII.

26 SCL, tomo XIII, sesión del 20 de octubre de 1826. 
En 1786 se habían instaurado dos intendencias, de Ejército y Provincia, en Chile. La primera, la Intendencia de Santiago extendía su jurisdicción desde el despoblado de Atacama, "aunque sin especificar los puntos exactos de los deslindes", hasta el río Maule e incorporaba el gobierno político-militar de Valparaíso $^{27}$. La segunda, la Intendencia de Concepción, se extendía desde el río Maule hasta la frontera indígena e incluía los gobiernos político-militares de Juan Fernández y Valdivia. El archipiélago de Chiloé constituyó un caso especial, ya que dependía del Virreinato peruano en lo político y militar ${ }^{28}$. En el mapa siguiente se representa el territorio abarcado por las intendencias del Reino de Chile ${ }^{29}$.

Un segundo caso excepcional se relacionó con la localidad de Coquimbo. María Teresa Cobos afirma que, durante la época de las intendencias, se pensó en crear una tercera, por motivos económicos y defensivos, que estaría conformada por los partidos de Copiapó, Huasco y Coquimbo. Dicha aspiración no se ejecutó sino hasta 1811, cuando el Congreso Nacional acogió el antiguo proyecto ante la petición de los representantes de La Serena, creando la provincia de Coquimbo ${ }^{30}$. Aunque poco se sabe sobre sus deslindes, Cobos sostiene que los límites de los tres partidos mencionados son tan imprecisos como identificar la circunscripción real de la nueva provincia. Ante este problema, expone ciertos puntos geográficos que nos permiten aproximarnos a los límites norte y sur de la nueva provincia. Según antecedentes de mediados del siglo XVIII, el deslinde norte del partido de Copiapó corría por una línea imaginaria de oriente a poniente situada alrededor de los $25^{\circ}$ latitud sur. Los hitos geográficos de esta línea eran el puerto Paposo al oeste y la localidad de las Vaquillas hacia el este. A su vez, el deslinde meridional de la nueva provincia sería el río Choapa, correspondiente al límite sur del partido de Coquimbo $^{31}$. Vemos a continuación el mapa que representa la división provincial vigente entre los años 1811 y 1823.

27 María Teresa Cobos Noriega, La división político-administrativa de Chile, 1541-1811, Valparaíso, Instituto de Historia, Vicerrectoría Académica, Universidad Católica de Valparaíso, 1989, 34.

28 Si bien a partir de 1784 la isla gozó del estatus de Intendencia, su jerarquía administrativa se transformó nuevamente en 1789, año en que la Corona española convirtió el archipiélago en gobierno político militar dependiente del Virreinato del Perú, condición que mantuvo hasta 1826, cuando fue incorporado efectivamente al territorio de la República de Chile. Ibid., 33 y 34.

29 Los mapas aquí expuestos pertenecen al proyecto FONDECYT N ${ }^{\mathrm{o}} 1051034$, "Representación cartográfica, ordenamiento político administrativo republicano, consolidación de la Nación y desarrollo en Chile", de los académicos José Ignacio González Leiva y Rafael Sagredo Baeza.

30 Cobos sostiene que hubo dos iniciativas durante el régimen colonial para modificar el estatuto legal de la región de Coquimbo. La primera pretendió transformar la circunscripción de Coquimbo y Copiapó en un gobierno político militar, tal como lo conformaban Juan Fernández, Valparaíso y Valdivia. La propuesta planteó fortificar la región, debido al precario estado defensivo en que se encontraba el litoral nortino. La segunda tentativa tuvo lugar a comienzos del siglo XIX y correspondió a la que acabamos de aludir en el cuerpo de nuestra investigación. La petición de este proyecto se encuentra en el documento titulado Solicitud del Cabildo de la Serena al Rey, para que se establezca la Intendencia de Coquimbo y se erija un Obispado, año 1808, incorporado como anexo documental en el trabajo de esta autora. En Cobos Noriega, op . cit., 38, 101, 102, 103 y 127-134.

31 Ibid., 42, 49 у 50. 


\section{INTENDENCIAS DEL REINO DE CHILE $1786-1812$}

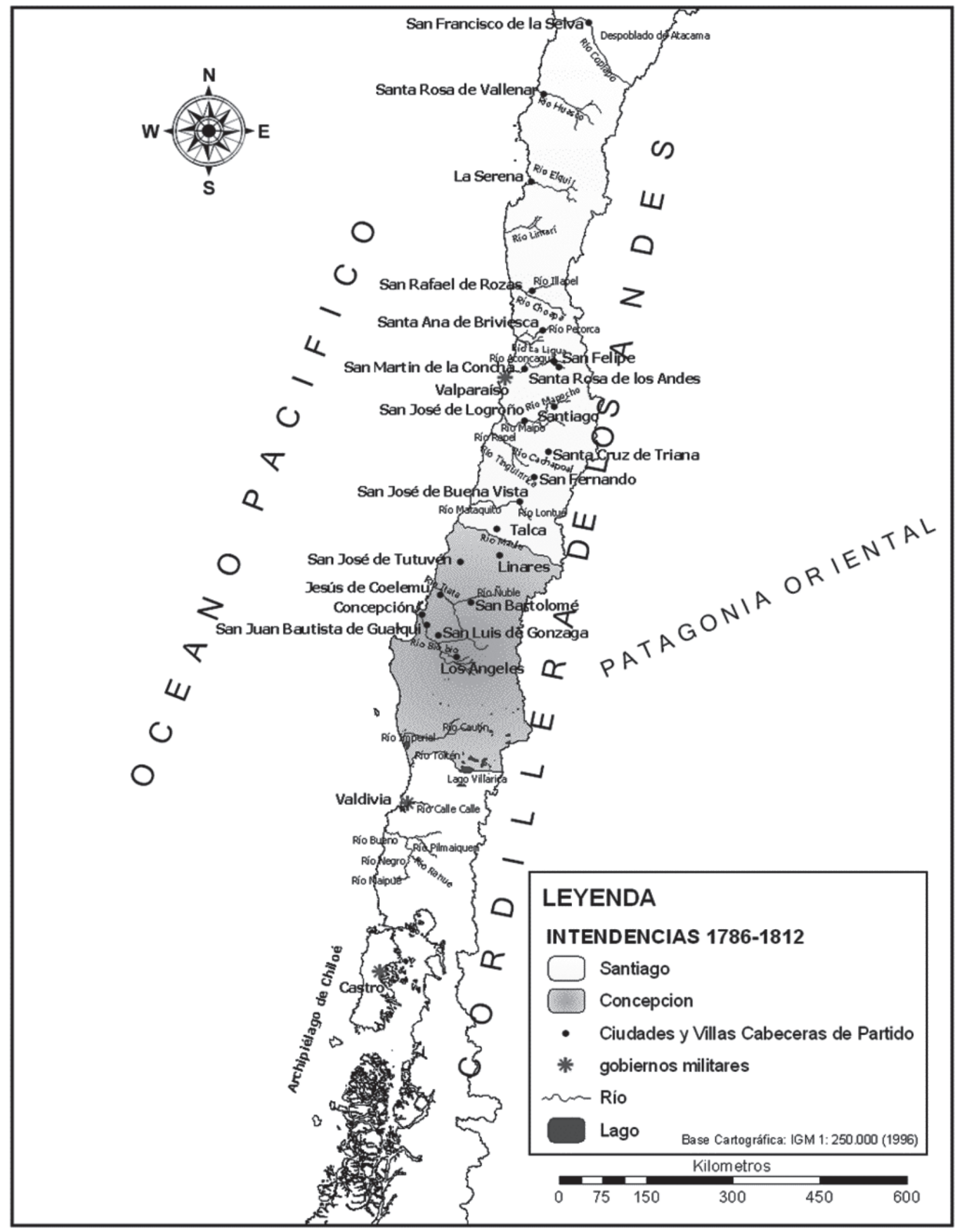

Fuente: Proyecto FONDECYT 1051034. 


\section{PROVINCIAS DE CHILE \\ 1812}

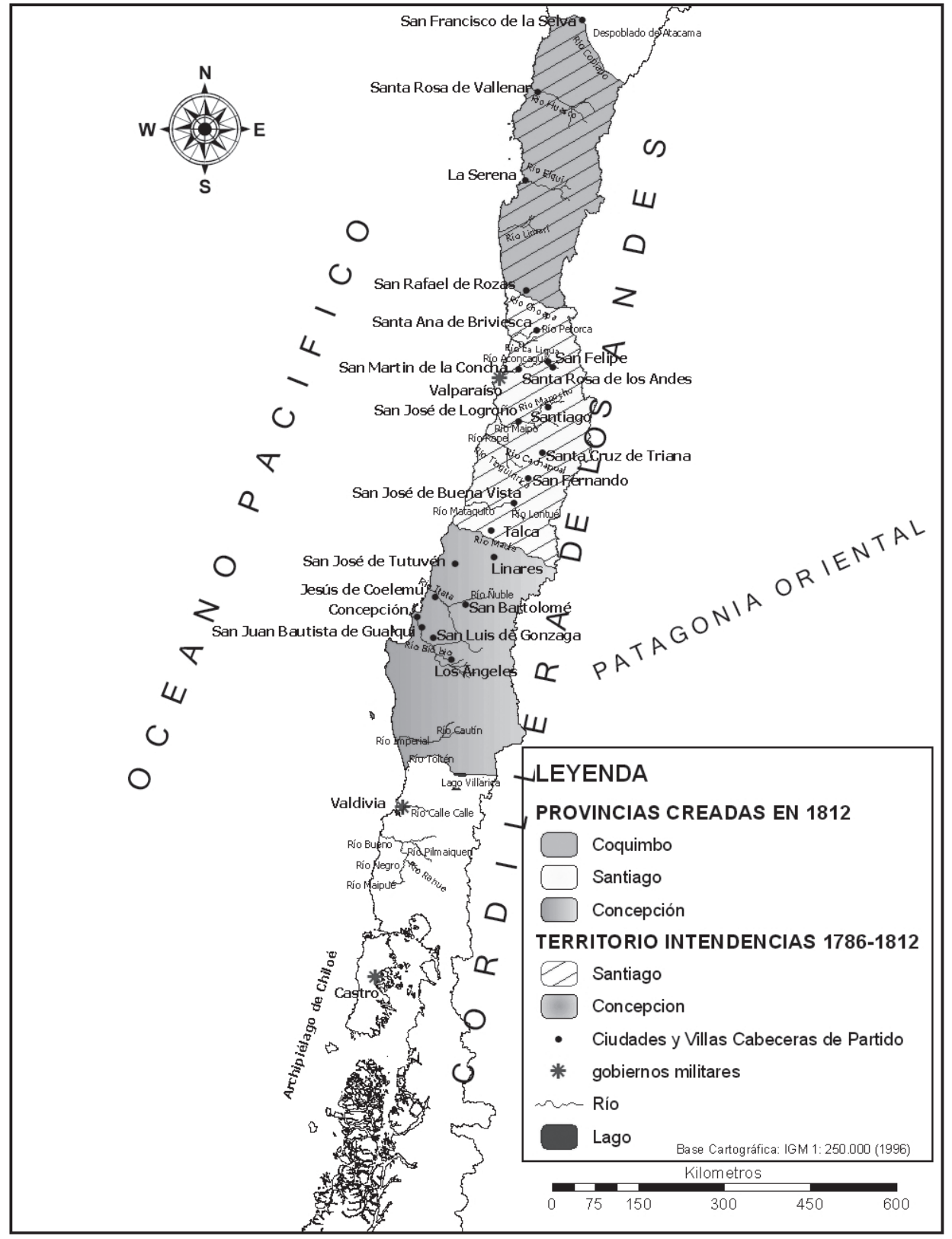

Fuente: Proyecto FONDECYT 1051034. 
Una vez en el poder los patriotas, la organización política del espacio chileno se plasmó de forma oficial en los proyectos y textos constitucionales del período, aunque resulta difícil establecer de manera concreta cuándo se promulgó por primera vez una disposición legal destinada a fraccionar el país con fines de administración pública $^{32}$. Esto porque el primer reglamento que instauró formalmente la división del territorio no se sancionó ni entró en vigencia. En cambio, aquellos que sí fueron aprobados, manifestaron tácitamente la existencia de un fraccionamiento políticoadministrativo, aunque solo en función de establecer las formas de representación nacional. El primer proyecto de Constitución aludido fue el de Juan Egaña de 1811, que estableció la división de la república en los artículos 173, 174 y 175:

“Art. 173. El estado político de la república se divide por ahora en tres departamentos, dependientes del gobierno soberano, cuyo pormenor de relaciones especificará la ley, uniendo en todos los casos posibles lo militar a lo civil y conservando la más estrecha dependencia de las delegaciones provinciales con la soberanía, sin perjuicio del buen orden.

Art. 174. Los tres departamentos serán por ahora Santiago, Concepción i Coquimbo. Habrá un gobierno político, militar en los dos últimos, y Santiago será dirigido del gobierno soberano en sus relaciones principales, teniendo por subalterno un intendente de provincia político y militar, cuyas facultades económicas y contenciosas establecerá la ley, sin perjuicio de los ramos ya destinados a los cabildos" 33 .

A diferencia del anterior, en el reglamento constitucional de 1812 se percibe una división política del territorio del Estado en la norma que definía la composición del Senado representativo. Se planteó implícitamente la distribución de tres provincias, en el artículo décimo, al exponer que "el Senado será representativo; correspondiendo dos a cada una de las provincias de Concepción y Coquimbo, y tres a la de Santiago" "34. Distinto ocurrió con la Constitución de 1818, porque esta realizó el primer fraccionamiento explícito, oficial y efectivo del espacio chileno, al señalar en su artículo primero que "el Estado de Chile se halla dividido por ahora en tres provincias: la capital, Concepción y Coquimbo"35.

32 Los proyectos y reglamentos constitucionales del período que dan cuenta de la existencia de una división político-administrativa son los siguientes: "Proyecto de Constitución para el Estado de Chile", compuesto por Juan Egaña en 1811 y publicado por orden de la Junta de Gobierno en 1813; "Reglamento Constitucional Provisorio", sancionado en 26 de octubre de 1812; "Proyecto de Constitución Provisoria para el Estado de Chile", sancionado y jurado el 23 de octubre de 1818; "Constitución Política del Estado de Chile", sancionada y promulgada en 30 de octubre de 1822. En Luis Valencia Avaria (compilador), Anales de la República, Santiago, Andrés Bello, 1986 y en SCL, tomo I, Congreso Nacional de 1811, XCIII.

33 Dichos artículos del "Proyecto de Constitución para el Estado de Chile", pertenecen a la Sección primera de los departamentos i delegaciones, inserta en el Título VII, llamado División política, económica y gradual de la República. En SCL, tomo I, Congreso Nacional de 1811, XCIII.

34 "Reglamento Constitucional Provisorio", sancionado el 26 de octubre de 1812. En Valencia, op. cit., tomo I, 49.

35 Este artículo del "Proyecto de Constitución Provisoria para el Estado de Chile", sancionado y jurado el 23 de octubre de 1818, perteneció al Capítulo IV, titulado De los gobernadores de provincia y sus Tenientes, concerniente al Título IV, Del Poder Ejecutivo. En ibid., tomo I, 75. 
Uno de los rasgos más visibles de la división político-administrativa de 1811, en función de los textos constitucionales aludidos, fue que no se instauraron las fronteras que delimitaban cada unidad territorial, ni se dispuso algo sobre sus capitales provinciales, situación que se mantuvo hasta 1823. Por lo tanto, las demarcaciones de las provincias, sus extensiones y jurisdicciones correspondieron a las mismas vigentes en 1810, primando la costumbre y tradición administrativa colonial. A pesar de ello, en 1811 se intentó demarcar las provincias existentes. Barros Arana sostiene que el Congreso Nacional de 1811 se percató tempranamente de "la deficiencia de los datos geográficos y estadísticos que eran más indispensables para conocer el verdadero estado social y administrativo del reino" 36 .

Con el objeto de lograr una administración óptima para el nuevo gobierno y designar la representación de las provincias, el Congreso de 1811 acordó levantar un censo nacional para registrar el número de habitantes por jurisdicción provincial, mostrando así tempranamente que se seguía el ejemplo de otros países. El documento constituyó un hecho aislado, pues las siguientes peticiones que se realizaron para levantar un censo general de la población no mostraron la intención de delimitar las unidades administrativas, sino que solo señalaron la urgente finalidad de establecer la representación nacional ${ }^{37}$. Sin embargo, resalta la inquietud de los patriotas por formar una estadística del entonces reino de Chile, aspecto que tuvo gran relevancia en los proyectos de división en una segunda etapa.

\begin{abstract}
"Como a la demarcación de las provincias en que debe dividirse el reino para su mejor gobierno y para designar la representación que en este debe tener cada una de ellas, debe preceder necesariamente un censo, padrón o enumeración exacta de todos sus habitantes, se empiece desde luego a practicar de todos los modos que se acostumbra hacer en otros países para que, del cotejo o confrontación que de ellos se haga, resulte el conocimiento de la verdad, o de lo que se aproxime de ella" 38 .
\end{abstract}

En este período tampoco se establecieron los centros administrativos provinciales. Una sutil excepción presentó la Constitución de 1818, pues fue el único reglamento del período que asentó una capital de provincia. La ciudad designada fue Santiago, la cual se erigió como centro político-administrativo de su provincia y de la nación. La existencia de ciudades con mayor preponderancia que otras llevó a una designación tácita. Concepción se instauró como capital en su antigua intendencia debido a su histórica tradición como centro político, militar y administrativo de la región. En la provincia de Coquimbo, La Serena manifestó desde los primeros años del siglo XIX su intención de constituirse en capital provincial ${ }^{39}$. A pesar de estos nombramientos implícitos, las dos últimas unidades administrativas permanecieron sin la designación oficial de sus cabeceras hasta 1823, año que

36 Barros Arana, Diego, Historia general de Chile, tomo VIII, Santiago, Editorial Universitaria y Centro de Investigaciones Diego Barros Arana, 2002, 404.

37 Véase $S C L$, tomo VI, sesiones del 1 y 7 de agosto de 1822.

38 SCL, tomo I, sesión del 9 de octubre de 1811.

39 Cobos Noriega, op. cit., 103. 
marcó el inicio de diversos proyectos de ordenación territorial que rompieron con la tradicional división político-administrativa de la Colonia ${ }^{40}$.

La Constitución de 1822 presentó ciertas variaciones respecto a la división del espacio, aunque no estableció el número de unidades departamentales. Una de ellas constituyó una modificación de tipo nominal y, por lo tanto, no influyó en el mapa político-administrativo del país. En su artículo 142, el código abolió las intendencias y dividió la república en departamentos -entidad que se mantuvo aproximadamente hasta $18234^{41}$. Además, por primera vez se hizo una delimitación explícita del territorio nacional al establecerse sus límites en el artículo tercero. Se optó por utilizar el criterio geográfico, de modo que las fronteras correspondieron a accidentes naturales. La disposición planteó los confines de la nación:

"ART. $3^{\circ}$ El territorio de Chile conoce por límites naturales: al sur, el Cabo de Hornos; al norte, el despoblado de Atacama; al oriente, los Andes; al occidente, el mar Pacífico. Le pertenecen las islas del Archipiélago de Chiloé, las de Mocha, las de Juan Fernández, la de Santa María y demás adyacentes" ${ }^{42}$.

Las razones de la continuidad en la composición de las provincias entre el régimen colonial y republicano son variadas. Entre 1811 y 1818 Chile se mantuvo a la expectativa de los acontecimientos ocurridos en España. El cautiverio de Fernando VII, y la consecuente representación de las provincias peninsulares a través de juntas de gobierno, hizo que gran parte de la reflexión sobre temas políticos estuviera enfocada a la situación respecto de España ${ }^{43}$. Luego el país se enfocó casi exclusivamente a las guerras de Independencia y gran parte de las motivaciones, esfuerzos y objetivos estuvieron puestos en la lucha. Hasta 1823, una de las principales preocupaciones del gobierno fue asegurar la emancipación y consolidarla frente a posibles amenazas, así como dotar al país de una Constitución que debía plantear los lineamientos generales del nuevo Estado. Estos factores, sumados a

40 Otro elemento que caracterizó esta etapa fue que tanto el proyecto constitucional de Juan Egaña como el código de 1818 otorgaron a las divisiones políticas un carácter provisorio. El primero mencionaba en su artículo 173 que "el estado político de la república se divide por ahora en tres departamentos". Asimismo, el artículo 174 planteó que "los tres departamentos serán por ahora Santiago, Concepción i Coquimbo". El segundo reglamento constitucional aludido expuso que "el Estado se halla dividido por ahora en tres provincias: la capital, Concepción y Coquimbo". Si bien el detalle de otorgarle una temporalidad limitada al ordenamiento territorial pudo deberse al carácter mismo de los proyectos fundamentales -constituciones provisorias en espera de ser reemplazadas por un código definitivo-, observamos ciertos indicios de que la clase política nacional o al menos parte de ella, tuvo el propósito de modificar en un futuro próximo la tradicional división del Estado. "Proyecto de Constitución para el Estado de Chile", en SCL, tomo I, Congreso Nacional de 1811, XCIII; y "Proyecto de Constitución Provisoria para el Estado de Chile", Artículo Primero, capítulo IV, título IV, sancionado y jurado el 23 de octubre de 1818, en Valencia Avaria, op. cit., tomo I, 75.

41 "ART. 142. Quedan abolidas las Intendencias, y el territorio se dividirá en departamentos, y estos en distritos". "Constitución Política del Estado de Chile", Capítulo Primero, Título VI del gobierno interior de los pueblos, sancionada y promulgada en 30 de octubre de 1822, en Valencia Avaria, op. cit., tomo I, 97.

42 Ibid., tomo I, 83.

43 Simon Collier, Ideas y políticas de la Independencia chilena 1808-1833, Santiago, Andrés Bello, 1977, 222. 
una crisis económica generalizada que no permitió lograr un financiamiento óptimo del sector público, hicieron que la organización del territorio del país con fines políticos y administrativos se postergara. Establecer una nueva división no se presentaba como un requerimiento urgente, pues la que el régimen colonial heredó a los patriotas aún era aplicable a la realidad chilena.

\section{EL NUEVO ORDENAMIENTO TERRITORIAL, CENTRALISMO ADMINISTRATIVO Y ROCES INTERPROVINCIALES}

La situación política hacia fines de 1822 era de gran inestabilidad y las tres provincias existentes participaron activamente en los sucesos que afectaron al país a lo largo de ese año. El desprestigio del gobierno de Bernardo O’Higgins, la hostilidad ante la centralización ejercida por la capital, manifestada en el quiebre de las relaciones entre las provincias, junto a una importante crisis económica que se hizo latente a partir de las mismas guerras de Independencia, contribuyeron a ello.

Debido a la crisis económica que afectó al país, la provincia de Concepción se halló especialmente perjudicada a raíz de una baja en la producción de sus campos. En los últimos meses de 1822 se presentaron signos de desabastecimiento y las repetidas demandas de sus habitantes no encontraron eco en el Gobierno, lo que llevó a un clima de general preocupación y descontento que afectó directamente a las relaciones interprovinciales. Las provincias de Coquimbo y Concepción plantearon sus reivindicaciones económicas y políticas al gobierno central, aludiendo al problema de la centralización mantenida por el gobierno de O’Higgins, y pretendieron una distribución más equitativa de las entradas del fisco, para lograr una administración eficaz y realizar obras que facilitaran las comunicaciones y el desarrollo económico. Las rivalidades con Santiago se acentuaron cuando las provincias de Coquimbo y Concepción señalaron al Director Supremo que su responsabilidad y deber estaban dirigidos hacia la nación entera. Se protestó que Santiago no actuara como capital de la nación, sino como capital de su provincia, obrando bajo sus propios intereses y desentendiéndose del compromiso con el país. Este hecho, y la crisis económica, fomentaron una situación de inestabilidad política, lo que provocó la desobediencia de Coquimbo y Concepción hacia el gobierno central, la convocatoria a sus propias asambleas provinciales y, finalmente, la abdicación del Director Supremo el 28 de enero de $1823^{44}$.

Desde entonces se intentó buscar la tranquilidad política interna a través de una reorganización institucional que asegurase el orden y la conciliación entre las tres

44 Véase Miguel Luis Amunátegui, La dictadura de O’Higgins, Santiago, Imprenta Barcelona, 1914, 407; Álvaro Góngora (coordinador), Chile 1541-2000. Una interpretación de su historia política, Santiago, Santillana, 2000, 134; Luis Vitale, Interpretación marxista de la historia de Chile. La Independencia política, la rebelión de las provincias y los decenios de la burguesía comercial y terrateniente, tomo III, Santiago, Prensa Latinoamericana, 1971, 97; SCL, tomo VI, sesión del 9 de septiembre de 1822 . 
provincias ${ }^{45}$. Después de algunas discusiones se acordó que estas escogieran un delegado para reunirse en un Congreso de Plenipotenciarios, el cual representaría a cada una de las jurisdicciones de forma equitativa ${ }^{46}$. Su tarea principal fue establecer un reglamento fundamental que regulara la administración de la república y que asegurara la participación política de las provincias. En este escenario, los plenipotenciarios acordaron, el 30 de marzo de 1823, el Reglamento Orgánico y Acta de Unión del pueblo de Chile $e^{47}$, cuyo objetivo primordial fue restablecer la unidad nacional y que tuvo como finalidades inmediatas instaurar las líneas generales del ordenamiento institucional de la república y convocar a un Congreso Constituyente encargado de elaborar una Carta Fundamental ${ }^{48}$. El reglamento destapó diversas problemáticas concernientes a la organización del territorio, que tuvieron gran importancia en el desarrollo posterior de la división político-administrativa. Entre ellas, la demarcación de los límites de cada jurisdicción, las capitales provinciales, los criterios de división y las dificultades técnicas existentes para la tarea, tales como el precario conocimiento geográfico del país y la falta de herramientas esenciales para elaborar un riguroso plan de demarcación.

Los roces entre las provincias y la capital evidencian una participación política activa, reflejada en la lucha contra el centralismo, característica más relevante de la fase de inestabilidad comprendida entre 1823 y 1830. La rivalidad con Santiago generó que, a partir de 1823 , las provincias velaran por una representación nacional equitativa. El Acta de Unión presentó el primer boceto de una nueva división político-administrativa de Chile y, al asegurar también la representación de las provincias, hizo presente sus demandas respecto a la división del territorio nacional. Ante el agrio recuerdo del poder centralizador de Santiago, participaron activamente a través de sus representantes, quienes no dudaron en pronunciarse una y otra vez sobre los proyectos de demarcación presentados por el gobierno y el legislativo. Expusieron sus diferencias y pretensiones en cuanto a los límites y capitales de sus respectivas circunscripciones, y se organizaron en gobiernos locales. Si bien las provincias no eran independientes del gobierno central, sí actuaron con bastante autonomía a través de sus asambleas. Ante cualquier roce con el gobierno, se insubordinaban y retiraban a sus representantes del Congreso, tal

45 Inmediatamente después de la abdicación de O’Higgins, se constituyó una Junta Gubernativa provisional, compuesta por Agustín de Eyzaguirre -presidente-, Fernando Errázuriz y José Miguel Infante, quienes debían ajustarse a un Reglamento Orgánico Provisional, de tipo constitucional. Sin embargo, la Junta no fue reconocida por las provincias, pues alegaron que no tenía un carácter nacional, exigiendo representación en el gobierno. Se acordó entonces la constitución del Congreso de Plenipotenciarios. Véase Julio Heise González, Años de formación y aprendizaje políticos 1810-1833, Santiago, Universitaria, 1978, 152.

46 La Asamblea Provincial de Coquimbo designó como representante para dicho Congreso a Manuel Antonio González, la de Concepción envió a Manuel Vásquez de Novoa y la provincia de Santiago nombró a Juan Egaña. Véase Valencia Avaria, op. cit., tomo II, 30.

47 "Reglamento Orgánico y Acta de Unión del pueblo de Chile", en ibid., tomo I, 109.

48 "Se estableció un poder ejecutivo unipersonal y provisorio; un legislativo a cargo de un Senado -conservador, formado por nueve miembros designados por asambleas provinciales a razón de tres por provincia- y un Poder Judicial independiente. Se declaraba vigente la Constitución de 1818 en todo lo que no fuese contraria al Acta de Unión de las Provincias”. En Heise González, op. cit, 153. 
como ocurrió a fines de 1822. Este fenómeno repercutió fuertemente en la configuración interna del territorio, debido a que las diversas localidades consideraron que la división del país debía realizarse en concordancia con sus demandas limítrofes, sin reparar en que era imposible satisfacer las exigencias de todos. Esto, junto a la disconformidad constante respecto de las delimitaciones jurisdiccionales, provocó que no hubiese una división estable entre 1823 y 1826. Las protestas contra el centralismo se manifestaron con plenitud en las discusiones suscitadas a raíz del proyecto federal de 1826, ya que las provincias apelaron constantemente a una proporcionalidad que asegurase la igualdad regional en la república, elemento que tuvo gran relevancia en los proyectos de división presentados en aquellos años.

\section{LOS PROYECTOS DE NUEVA DIVISIÓN DEPARTAMENTAL}

A partir de marzo de 1823 el proceso de división político-administrativa tomó un nuevo rumbo que se caracterizó por una elaboración consciente de la organización interior del territorio nacional, reconociéndose su influencia para lograr una mejor gestión del Estado, que fue percibida por los políticos chilenos como un elemento de progreso nacional, así como de cada una de las fracciones territoriales que lo integraban. La racionalización del nuevo ordenamiento constituyó el próximo paso en la construcción y organización del Estado. Ante la necesidad de organizar la administración en todas las regiones del país y asegurar una equitativa participación de las provincias en el gobierno, por medio de un sistema de representación local, desde 1823 en adelante se inició un proceso caracterizado por un creciente y constante interés por segmentar al país en diversas unidades administrativas. Así, Ramón Freire mencionó en 1825 que dividir el espacio nacional en un mayor número de jurisdicciones era, sin duda, una ventaja para la administración y que proporcionaría inmensos bienes para el país ${ }^{49}$. Entonces se enunció que el tema era de trascendental importancia y se manifestó la urgencia con que debía tratarse y aprobarse el proyecto. En octubre de 1825 lo señaló nuevamente, al declarar que

"asunto es este que, siendo de tan grande importancia y debiendo producir los mayores resultados, sin embargo, no parece digno de dilatarse en largas explicaciones y observaciones sobre él; porque tal es, tan obvia y tan íntima y general de todos los chilenos, la persuasión y conocimiento sobre la necesidad de esta medida" 50 .

Como reflejo de una época marcada por el anhelo de progreso y por la adopción continua de ideales e instituciones foráneas, los dirigentes nacionales aludieron a la prosperidad que conllevaría la medida, aludiendo a los ejemplos que ofrecían naciones como Francia y los Estados Unidos de Norteamérica. Esta última nación

49 SCL, tomo XII, sesión del 27 de julio de 1826.
Idem. 
apreciada como modelo de libertad y desarrollo, aspectos que se exacerbaron aun más durante la efervescencia federal de 1826.

"El grado inmenso de prosperidad que a la Francia ha llegado, se atribuye principalmente por los economistas y políticos a la acertada división territorial que se hizo durante la revolución; y la política de los Estados Unidos del Norte de América, que es el modelo clásico que tenemos en nuestro continente, lejos de ser por conservar gran territorio y población, ha sido constantemente por subdividirse, como en efecto se ha verificado en algunos de los Estados después de la declaración de su independencia y de haberse dado su constitución federal" ${ }^{\prime 1}$.

Las intenciones de ejecutar esta empresa se plasmaron en los textos constitucionales del período, tales como el Acta de Unión de 1823, la Constitución Política debida a Juan Egaña y el ensayo federal de 1826, donde se hizo un fraccionamiento explícito del territorio chileno. Con motivo de la elaboración de cada uno de ellos se suscitó un rico debate en que las provincias manifestaron sus motivaciones e intereses particulares a través de sus representantes, quienes plantearon repetidas modificaciones y reformas a los planes de división territorial.

En esta segunda fase se añadieron diversos elementos a considerar en torno a la situación territorial del país ${ }^{52}$. Uno de los rasgos más notorios es que se cambió la organización interior de la Colonia por una nueva, que consistió en un mayor número de unidades administrativas. A partir de 1823, Chile no volvió a concebirse en tres provincias, pues el espacio nacional se fragmentó progresivamente. Por lo demás, el Acta de Unión estableció diversos puntos que marcaron la pauta en la discusión que se formó posteriormente respecto a la organización interior del territorio, algunos de los cuales fueron los responsables de la compleja tramitación que tuvo el proyecto de división y deslinde de las provincias. Esto desencadenó que por cerca de tres años - de 1823 a 1826- el país no tuviera una división político-administrativa estable que le permitiese administrar óptimamente su territorio. Finalmente esta se estableció en el artículo 24 del Acta de Unión y determinó las siguientes demarcaciones:

"Artículo 24.- Chile, en su estado actual se dividirá inmediatamente en seis departamentos, que cada uno comprenda la extensión que haya de mar a cordillera, limitándose de norte a sur en esta forma:

Primer departamento: desde el despoblado de Atacama, hasta el río de Choapa.

Segundo y tercer departamentos: desde Choapa hasta las riberas de Lontué.

Cuarto y quinto departamentos: desde Lontué hasta el Biobío, y sus fortalezas al sur y adyacencias.

Sexto departamento: de todas las poblaciones que posee o adquiera el Estado desde el Biobío hasta sus límites en el sur" 53 .

51 Idem.

52 En lo nominal hubo una cierta confusión en torno a qué unidad administrativa instaurar. Si bien en los textos constitucionales se establecieron departamentos o provincias, constantemente en proyectos de ley, mociones y peticiones provenientes del Legislativo y del Ejecutivo, se habló de provincias, departamentos o intendencias, otorgándoles el mismo significado.

53 "Reglamento Orgánico y Acta de Unión del pueblo de Chile", en Valencia Avaria, op. cit., tomo I, 111 y 112 . 
La división se planteó solo en líneas generales, pues si bien estableció el fraccionamiento de la república en seis departamentos, no fijó la totalidad de los deslindes entre ellos. El sexto departamento constituyó un caso especial al abarcar la zona fronteriza, Valdivia y Chiloé, que formaban territorios aislados en el espacio chileno debido a la presencia indígena, en el primero, y española, en el segundo. Ante esta problemática, el sexto departamento exteriorizó discretamente las aspiraciones de incorporar efectivamente estas zonas geográficas al territorio nacional, revelando dos realidades: un dominio existente y otro por adquirir. La primera tuvo relación con la necesidad de señalar la pertenencia al Estado de aquellas localidades aisladas al sur del río Biobío y en medio del dominio indígena, como la jurisdicción de Valdivia, enclave que no había sido mencionado anteriormente. La segunda, en cambio, exhibió la intención palpable de incorporar el archipiélago de Chiloé a la jurisdicción nacional. Recordemos además que la Constitución de 1822 -la primera que estableció las fronteras nacionales- estipuló que Chiloé pertenecía al Estado chileno y que el límite sur del país se encontraba en el Cabo de Hornos, sin precisar nada sobre la región comprendida entre este deslinde y el río Biobío. Estas cláusulas evidenciaban la discontinuidad del espacio nacional, contrastando así las pretensiones de los dirigentes chilenos con la realidad geopolítica de 1823, la que mostraba que no existía una posesión efectiva de todo el territorio nombrado chileno.

A pesar de que no se hizo una delimitación completa de las provincias, por primera vez se aludió a ellas, lo que convierte al fraccionamiento del Acta de Unión en el primer esquema de división político-administrativa que realizó Chile como nación independiente. Dicha imprecisión limítrofe se reconoció en los artículos 24 y 25, así como en las disposiciones oficiales del período, donde la preocupación por designar un cuerpo especializado que centrase su atención en la demarcación del territorio, a partir de estudios y observaciones de la realidad territorial, constituyó otro elemento novedoso que diferenció el nuevo ordenamiento del anterior, en que solo hubo una enumeración de las provincias existentes.

“Art. 24. (...) El Poder Ejecutivo de acuerdo con el Senado, procederán inmediatamente a formar los deslindes topográficos de cada uno de estos departamentos.

Art. 25. Si cumplidos sesenta días de la fecha de esta acta no están verificadas las demarcaciones de los departamentos, queda responsable el Senado de esta omisión"54.

Si bien el Acta de Unión delegó en el Ejecutivo, con acuerdo del Senado, la tarea de establecer los límites departamentales, Ramón Freire emitió dos comunicados con autoridad de decreto, el 23 de abril de 1823, donde creaba una comisión especial para efectuar los estudios geográficos pertinentes, con miras a formar una correcta delimitación de las fronteras interprovinciales. Para ello ordenó a las autoridades y funcionarios del Estado prestar toda la ayuda que la comisión solicitara para el ejercicio de su función. Una vez cumplida la tarea, el Director Supremo entregaría el nuevo proyecto de deslinde al Senado, en espera de su aprobación.

$54 \quad$ Ibid., 112 . 
"Dando cumplimento a lo prevenido en el artículo 24 del acta de unión, nombro en comisión para que me propongan un proyecto de división y deslinde topográfico de los departamentos del Estado, en la forma que previene dicho artículo, a don Manuel Salas, don Juan Egaña, don Santiago Fernández, don Antonio Pantaleón Fernández y don José María Argandoña.

La comisión evacuará este encargo en el término perentorio de quince días, y para su mejor desempeño, todos los generales, autoridades y funcionarios del Estado, de cualquiera clase y condición que sean, franquearán, a requisición de la comisión, todos los documentos, auxilios y servicios que pidiese a este efecto" 55 .

La comisión elaboró así un primer proyecto de demarcación y presentó su informe al Poder Ejecutivo el 6 de mayo de 1823. Ofreció diferentes opciones de deslindes departamentales, tomando como base el Acta de Unión y sus disposiciones, a partir de las cuales debía regirse cualquier ordenamiento posterior. Una primera alternativa presentó la línea divisoria entre el segundo y tercer departamento a través del río Maipo así como la del cuarto y quinto por el río Nuble, continuando por el Itata.

"Señor: A la Comisión destinada para proponer las demarcaciones que deben formar las nuevas Intendencias establecidas en el acta orgánica de unión, le ha parecido por dictamen unánime y conforme, que la fracción que debe hacerse de la provincia de Santiago para las dos Intendencias, sería conveniente verificarla por río de Maipo, desde su nacimiento hasta su embocadura; quedando así el departamento de la capital comprendido entre los ríos de Choapa y Maipú y con los principales puertos de mar y cordillera que son tan necesarios al punto central del gobierno y los recursos. La otra Intendencia se deslindaría entre Maipo y Lontué que, debiendo ser agricultora, comprende grandes planos, muchas aguas, proporción para excelentes canales, y todos los recursos de la industria agraria.

Al pasar a la fracción que debe formar las dos Intendencias comprendidas entre Lontué y Biobío, la pluralidad de votos de la Comisión ha sido: que si se ha de buscar un deslinde natural por ríos, como se ha practicado en las demás Intendencias, la mejor división que se presenta es desde el nacimiento del río Ñuble hasta su confluencia con los demás que forman el Itata, siguiendo después este gran río hasta su embocadura en el mar; quedando así seis partidos, a más de los fuertes de ambas orillas de Biobío y sus adyacencias de sur, para formar la Intendencia de Concepción, que queda con el precioso puerto de Talcahuano, el dominio de las islas inmediatas y su jurisdicción hasta Arauco y el río Carampangue" 56 .

La segunda alternativa planteaba circunscribir el quinto departamento entre el río Biobío, por el sur, y la línea que corría por el límite norte del partido de San Carlos, continuando por el límite sur del partido de Quirihue. Con esto, Concepción incorporaría el partido de San Carlos, pero excluiría el de Quirihue, que sería parte de la Intendencia de Maule. Esta correspondería al cuarto departamento,

55 SCL, tomo VII, sesión del 23 de abril de 1823.

56 SCL, tomo VII, sesión del 7 de mayo de 1823 . 
aunque el informe no manifestó explícitamente sus linderos jurisdiccionales. La comisión lo indicó de la siguiente manera:

“También ha creído la pluralidad de la Comisión que, si aun se quiere proporcionar más recursos, dependencias y extensión de jurisdicción a Concepción, se puede formar una línea divisoria que, corriendo desde la cordillera y dejando al sur el partido de San Carlos según los deslindes que hoy tiene, siga hasta el mar por la división de Quirihue, cuyo partido quedará al lado del norte para formar la Intendencia del Maule. Así podrá también proporcionarse que todas las fronteras orientales expuestas a invasión de indios quedasen bajo el mando militar y civil de Concepción, bien que siempre se hallará muy distante de los auxilios de aquella capital; así de este modo quedará la Intendencia del Maule con el mayor río navegable del país y un puerto marítimo bastante regular a mas de los recursos para un buen astillero. Tales son los únicos arbitrios de demarcación que han ocurrido a la pluralidad de la Comisión, asentada la base del artículo 24 del acta orgánica de unión, en que se previene que los deslindes y divisiones de las Intendencias deben correr por la líneas de mar a cordillera y la que les presenta la extensión proporcional de ambos terrenos, la proximidad de los recursos a las respectivas capitales y la consideración de que siendo Talca la ciudad de mas población parece ser acreedora a que se establezca allí la capital" ${ }^{57}$.

Una tercera alternativa propuso que la línea divisoria entre el cuarto y el quinto departamento fuese a través del río Diguillín hasta la villa de Hualqui. Desde ahí, se planteó trazar una línea recta, ficticia, hasta tocar con el río Biobío. De esta forma quedaría el departamento de Concepción comprendido entre la delimitación anterior, por el sur, y el río Lontué, por el norte, e incluiría en su jurisdicción a los partidos de Florida, Coelemu, Chillán, San Carlos, Parral, Quirihue, Cauquenes, Linares y Talca. Asimismo, designaba como quinto departamento la Intendencia de Fronteras. Su capital sería Los Ángeles y su jurisdicción comprendería Laja, Rere, Pemuco y los fuertes de Nacimiento, Santa Juana, Arauco, Colcura y San Pedro.

"Y el señor don Pantaleón Fernández, como voto particular, ha propuesto que la división del $4^{\circ}$ y $5^{\circ}$ departamento se verifique en esta forma, a saber: por una línea que, corriendo desde Lontué hasta Biobío, resulten dos Intendencias, la primera nombrada de Concepción contendrá esta capital y su jurisdicción los partidos de Florida, Coelemu, Chillán, San Carlos, Parral, Quirihue, Cauquenes, Linares y Talca. La segunda se nombrará Intendencia de Fronteras, cuya capital será los Ángeles y su jurisdicción de las provincias de la Laja y Rere, los fuertes de Nacimiento, Santa Juana, Arauco, Colcura, San Pedro y el lugar de Pemuco. De este modo, la demarcación de la provincia de Fronteras, correrá por el de Diguillín, oriente poniente hasta la villa de Gualqui, cortando línea recta desde esta villa al sur hasta tocar con el Biobío; y la provincia de Concepción vendrá corriendo por todo el río de Lontué hasta tocar en el mar, y desde allí hasta la embocadura del Biobío, comprendiendo lo que hay entre estos puntos y la línea de demarcación que se ha fijado a la que se nombra provincia de Fronteras" 58 . 
Toda la discusión de la comisión se relacionó con la zona sur del país, por lo que dejaron en statu quo las delimitaciones nortinas. En el debate, la delegación privilegió la primera alternativa y presentó su informe al Director Supremo, quien buscó el acuerdo del Senado Conservador, luego de hacer algunas observaciones en un comunicado fechado el 21 de mayo de 1823, y rigiéndose siempre por los estatutos del Acta de Unión.

"Excmo. Señor: El Director Supremo del Estado incluye al Senado Conservador el proyecto de demarcación de departamentos que le ha presentado la comisión nombrada al efecto.

Parece arreglado el dictamen de la pluralidad de los individuos de dicha comisión.

De todos modos, es preciso dar cumplimiento a la ley orgánica.

El artículo 24 previene que la división se verifique inmediatamente.

El Senado es responsable si no se hallase formada para el 31 de Mayo, y ella debe hacerse por fajas, que cada una comprenda la extensión que hay de mar a cordillera, y en ninguna manera por líneas tiradas de Norte a Sur, como que en este último caso habría departamentos que quedasen sin puertos, con una anchura absolutamente desproporcionada y con mucha extensión de Norte a Sur, que haría demasiado molestos los recursos que los pueblos de la comprensión de cada departamento tuviesen que hacer a la ciudad cabecera" 59 .

Tanto el proyecto entregado por la Comisión, como las observaciones realizadas por Ramón Freire, expusieron elementos a considerar en la demarcación del espacio que permitieran formar una división favorable a las jurisdicciones. Ejemplo de ello fue que los deslindes se establecieron a partir de un trazado horizontal, de oriente a poniente, para lograr la uniformidad del territorio y para que cada unidad administrativa no careciera de puerto marítimo, pasos cordilleranos y recursos hídricos que contribuyeran a su desarrollo interno. La presencia de estos tres últimos componentes se exhibió como algo beneficioso para las provincias, pero no se estableció como un requerimiento indispensable a la hora de dividir el territorio nacional. Se obedeció a un criterio de demarcación natural de las circunscripciones en vez de recurrir a un fraccionamiento artificial del territorio, buscando así una organización que se ajustara a la realidad geográfica. De este modo se hizo evidente el propósito de utilizar accidentes geográficos como líneas divisorias, optando por una delimitación a través de los cursos de los ríos, pues estos se ajustaban tanto al criterio de horizontalidad como al geográfico. También se planteó la proporcionalidad territorial, con el objetivo práctico de mantener la proximidad entre las localidades de cada departamento y sus respectivas capitales, para atenderse o auxiliarse mutuamente en casos de adversidad, cuestión de vital importancia en vista de los acontecimientos que afectaron a la antigua provincia de Concepción durante el año 1822. Otro factor fue considerar el alcance de la prestación de servicios de la capital hacia el resto del departamento, elemento esencial para obtener una gestión pública eficiente. De la proporcionalidad entre los depar-

59 SCL, tomo VII, sesión del 21 de mayo de 1823. 
tamentos solo se habló en cuanto a la extensión territorial de las unidades políticoadministrativas. Posteriormente, este elemento se extendió hacia otras áreas, al invocar la proporcionalidad de recursos y población, aspecto que tomó aires políticos al adoptar los conceptos de equidad e igualdad, y que fue uno de los rasgos más sobresalientes de la segunda etapa que se analiza. Estas particularidades, en conjunto, también se exhibieron en comunicados posteriores, constituyendo una constante para los demás planes de división.

El 11 de junio de 1823 se realizó la segunda modificación al proyecto de división político-administrativa de la república, establecida inicialmente en el Acta de Unión. El nuevo plan fue presentado por el Senado, y ofrecía un mayor fraccionamiento del espacio al aumentar a ocho el número de departamentos. Se incluyeron territorios antes no considerados y, por primera vez, se expuso un bosquejo de las capitales de cada unidad administrativa.

"Primer departamento: desde el despoblado de Atacama hasta la Quebrada del Negro, deslinde antiguo, entre Petorca e Illapel; su capital, la ciudad de la Serena.

Segundo departamento: desde la Quebrada del Negro hasta la cuesta de Chacabuco y su cordón hasta el mar; su capital, la ciudad de Aconcagua.

Tercer departamento: desde Chacabuco hasta el río Cachapoal; su capital, la ciudad de Santiago.

Cuarto departamento: desde Cachapoal hasta el río Maule; su capital, la ciudad de Talca. Quinto departamento: desde el Maule hasta el río Diguillín, tomado en su nacimiento de la cordillera a su entrada en Itata, y de aquí tirando la línea divisoria con dirección a la angostura Gualqui, que une al Biobío, concluyendo a la entrada de este al mar; su capital, la ciudad de Concepción.

Sexto departamento: todo el territorio que se contiene desde la línea del anterior departamento hasta la cordillera, quedando en su comprensión el partido de Lautaro; su capital, la ciudad de los Ángeles.

Sétimo departamento: el territorio comprendido en la jurisdicción que conoce hoy el gobierno de Valdivia; su capital, Valdivia.

Octavo departamento: el territorio que se comprende en la jurisdicción que conoce hoy el gobierno de Chiloé; su capital, San Carlos"60.

Aludiendo a razones de conveniencia pública, al reflexionar en torno a los recursos que podían proporcionar los terrenos, así como a las motivaciones y costumbres de sus habitantes, el mensaje planteó nuevos factores para que la organización interior del territorio fuera de provecho para todos.

"Para la división y demarcación se debe atender, entre otras cosas, a la proporción de las relaciones interiores y exteriores, al clima, usos, inclinaciones, genio e índole de los nuevos provincianos, a la feracidad o avaricia de los terrenos. Todos estos sujetos

60 Luego de recibir el informe enviado el 21 de mayo por el Director Supremo, el Senado Conservador discutió el proyecto de demarcación elaborado por la comisión, en tres sesiones públicas, y planteó enseguida su reforma a la división política del territorio. SCL, tomo VII, sesión del 11 de junio de 1823 . 
particulares que hacen la felicidad relativa, forman también la absoluta y general. El proyecto da por capitales a Talca y Concepción ciudades aisladas, sin poder socorrer ni ser socorridas por sus pueblos subalternos en sus respectivas estaciones. Frecuentes y sensibles son las privaciones que a las veces sufre Concepción, sin que la Providencia pueda venir en su auxilio por su situación topográfica" ${ }^{61}$.

Los senadores de 1823 exteriorizaron las antiguas desavenencias suscitadas entre las provincias durante el año anterior, recordando un agrio período que generó diversas desavenencias de repercusión nacional. Al evocar las constantes disputas entre las provincias, el Senado apuntó al establecimiento de un equilibrio entre los departamentos para asegurar su igualdad y prosperidad, de modo que quedasen en el pasado antiguos celos y discordias. Conscientes de que la división político-administrativa constituía un instrumento de progreso para la nación, señalaron "facilitemos las relaciones en la forma posible, hermánense las costumbres de las capitales con sus pueblos, confórmense los caracteres i habitudes, i serán indudables, visibles i rápidos los progresos ventajosos de la división i demarcación de las intendencias"62. No obstante, esta segunda modificación originó un amplio debate entre el Legislativo y el Ejecutivo e incluso generó momentos de tensión entre ambos poderes. Aumentar el número de departamentos hizo que la Suprema Magistratura calificara el nuevo proyecto como inconstitucional, pues contravenía la disposición acordada por los plenipotenciarios, reunidos en congreso, de establecer seis departamentos. La justificación brindada por el Director Supremo giró en torno a que no se transgrediese el Acta de Unión por gozar de carácter constitucional, cuando sostuvo que

"habiendo prometido y jurado a la nación cumplir el acta orgánica de unión, declarado nulo cuanto hiciese en contrario, y mandado no sea obedecido en ello; no pudiendo, por razón del alto cargo que administro, atacar ni permitir sea atacada la ley fundamental dictada por la nación reunida, y que me eligió Director Supremo, encargándome su puntual e indefectible cumplimiento" 63 .

Los mismos argumentos presentaron sus ministros, quienes afirmaron que el Acta de Unión solo podía modificarse a través de la misma autoridad que la dictó, es decir, por la nación reunida en Congreso Nacional ${ }^{64}$. Para ellos, la

61 Idem.

62 Idem

63 SCL, tomo VII, sesión del 18 de julio de 1823.

64 Una vez disuelto el Congreso de Plenipotenciarios, el nuevo Director Supremo asumió la dirección de la república en colaboración con un Senado Conservador de nueve miembros. Este cuerpo sesionó hasta comienzos de agosto de 1823 y se compuso con los miembros designados por las asambleas provinciales, quienes nombraron a tres senadores por provincia; Gregorio Cordobez, el presbítero don Marcos Gallo y Manuel Antonio González por Coquimbo; los señores Fernando Errázuriz, Agustín de Eyzaguirre y José Miguel Infante, por Santiago, y los señores Pedro Arce, Pedro Trujillo y Manuel Vásquez de Novoa por Concepción. La mayor parte de ellos no concluyeron el período designado, razón por la cual se nombraron senadores suplentes, aunque algunos de ellos tampoco pudieron incorporarse. En Valencia, op. cit., tomo II, 31 y 32; Heise González, op. cit., 153 y Barros Arana, Diego, Historia General de Chile, tomo XIV, Editorial Universitaria y Centro de Investigaciones Diego Barros Arana, Santiago, 2005, 38 y 39. 
demarcación del Senado Conservador estaba "en terminante y diametral contravención del artículo 24 del acta orgánica y del artículo único, capítulo $1^{\circ}$, título III de la Constitución provisoria" 65 . Ante esta problemática, Ramón Freire firmó un decreto el 16 de julio de 1823 que declaró la inconstitucionalidad de la demarcación del Senado y que suspendió todo acuerdo al respecto, hasta la reunión del Congreso Nacional ${ }^{66}$. Más tarde la discusión se renovó en el Congreso Constituyente y, apaciguados los ánimos, se subrayó la importancia de establecer una división político-administrativa, reanudándose el intercambio de opiniones, interumpido por las discusiones aludidas y por la persistencia del Senado Conservador en aprobar un proyecto precipitadamente, sobre los elementos que debían considerarse al crear los deslindes apropiados de cada circunscripción.

Con motivo de la preparación de la nueva Constitución Política del Estado, y debido a la continua postergación que sufrió el proyecto de división del territorio, en las sesiones del Congreso Constituyente se retomó la importancia de sancionar la organización interior con prontitud. El diputado Jacinto Urrutia expuso esta y otras problemáticas que giraban en torno a la división política del Estado en cuatro comunicados. Sostuvo que "el plan de departamentos formado por el Congreso de Plenipotenciarios, sin duda alguna debe ser una de las bases fundamentales para la formación de la Constitución que nos debe regir"67. Presentó además los criterios generales bajo los cuales tenía que regirse la nueva demarcación al afirmar que los departamentos no carecieran "de puerto marítimo i boquete para la otra parte de los Andes, según lo permita la naturaleza de cada uno"68. Planteó la cautela con la que se debía tratar el asunto debido a la existencia de intereses locales, pues

"por motivo alguno debe dejarse la división de dos departamentos a la discusión de los representantes que a ambos correspondan, sino a los de toda la nación; pueda ser que los primeros abriguen bajo de sí más bien a algún pueblo de donde sean natos su mayor parte, y suceda que acaso pretendan ventajas sobre la división del departamento que les toque" 69 .

Este texto constituye uno de los primeros que exterioriza claramente la presencia de ambiciones locales y su eventual influencia en las discusiones sobre división político-administrativa del Estado. De aquí también la inquietud por que la división fuese sancionada por la legislatura nacional y propuesta por comisiones especiales, en vez de por las partes directamente involucradas. Inclinarse por intereses

65 El comunicado emitido por los ministros de Estado al Director Supremo se firmó el 15 de julio de 1823. SCL, tomo VII, sesión del 18 de julio de 1823.

66 El decreto se firmó el 16 de julio de 1823, por Ramón Freire, Mariano Egaña, Diego J. Benavente y Santiago Fernández. Véase, SCL, tomo VII, sesiones del 30 de junio, del 2, 4, 11 y 18 de julio de 1823

67 SCL, tomo VIII, sesión del 27 de agosto de 1823.

68 Idem.

69 El documento se firmó el 2 de agosto de 1823. SCL, tomo VIII, sesión del 3 de septiembre de 1823 . 
propios en desmedro de otras circunscripciones fue percibido por el diputado como una limitante para lograr el bien general de la nación, pues contribuía a la permanencia de los roces interprovinciales. Por eso afirmó:

“el beneficio que un departamento supere con perjuicio de otro ¿cuál es la ventaja que resulta a la nación entera? [...] donde viéremos beligerante la particularidad con el abatimiento del vecino, donde viéremos pedir a la jurisprudencia la comodidad con perjuicio de otra porción semejante, ¿cuáles ventajas serán las que al bien público puedan resultar? La discordia y enemistad y generalmente las inquietudes, estoy seguro serán las que se prometen"70.

Un tercer proyecto que nuevamente intentó modificar la división del Acta de Unión fue presentado por la Comisión de Constitución al Congreso Constituyente en la sesión del 1 de septiembre de 1823. Si bien este mantuvo la cantidad de departamentos propuestos por el Senado Conservador, el plan cambió algunos de los límites señalados en el proyecto del 11 de junio.

"El territorio del Estado se divide en ocho departamentos; los departamentos en delegaciones y las delegaciones en distritos.

$1^{\circ}$ El departamento de Coquimbo, comprenderá desde los confines del Estado al Norte, hasta el río de Choapa; su capital, la ciudad de la Serena.

$2^{\circ}$ Departamento de Aconcagua, que comprende desde el río de Choapa hasta el río de Aconcagua, y Quillota, nombrado Chile; su capital, la ciudad de San Felipe.

$3^{\circ}$ Departamento de Santiago, que comprende desde el río Chile hasta el río Cachapoal; su capital, la ciudad de Santiago.

$4^{\circ}$ Departamento de Maule, que comprende desde el río Cachapoal hasta el río de Maule; su capital, la ciudad de San Agustín de Talca.

$5^{\circ}$ Departamento de Chillán, que comprende desde el río Maule hasta el río Itata; su capital, la ciudad de Chillán.

$6^{\circ}$ Departamento de Concepción, que comprende desde el río Itata hasta el río Biobío; su capital, la ciudad de Concepción.

$7^{\circ}$ Departamento de Valdivia, que comprende desde el río Biobío hasta los confines del Estado al Sur; su capital, la ciudad de Valdivia.

$8^{\circ}$ Departamento de Chiloé, que comprende todas las islas de aquel archipiélago; su capital, la ciudad de San Carlos" $"$.

La Comisión de Gobierno presentó al Congreso el 17 de septiembre un proyecto de ley acompañado de un informe aclarativo que por primera vez exponía problemas de gran relevancia en el proceso de configuración del territorio a partir de la observación de la realidad chilena, y que resumía en cierto modo los planteamientos anteriormente emitidos. Con el avance del tiempo, los criterios de fraccionamiento fueron cada vez más generales y dejaron de reparar en especificidades, aunque la gran novedad fue que la Comisión exhibió la precariedad de herramien-

\footnotetext{
70 Idem.

71 SCL, tomo VIII, sesión del 1 de septiembre de 1823.
} 
tas esenciales que poseía el país para realizar una demarcación óptima del espacio nacional, advirtiendo la carencia de planos geográficos y de una estadística a nivel nacional, así como de un conocimiento aproximado de la población.

"La Comisión de Gobierno ha visto detenidamente los documentos, planos y oficios relativos a la partición del Estado en provincias o intendencias, y estando persuadida del interés que resulta y de que este es el voto general de la nación que aspira, como debe, a sus adelantamientos y felicidad; no ha dudado un solo momento para opinar que la predicha partición debe practicarse tan pronto como pueda hacerse; pero cree que no habiendo hasta hoy planos geográficos y topográficos del país, la estadística general de él, ni aun siquiera un conocimiento aproximado de la población, producciones y arbitrios de cada uno de los partidos en que ha de dividirse, es muy aventurada cualquiera división que se adopte y mucho mas, sin que, ante todas cosas, se sepa con fijeza de qué caudales han de subsistir los funcionarios y empleados nuevos que deben haber; cuyo conocimiento ha de resultar necesariamente del plan de hacienda que está formándose" 72 .

Ya se había planteado la atención a los recursos, la extensión de los terrenos y su fertilidad, pero poco se reparó en que para incluir estos elementos en la demarcación, debía hacerse un estudio riguroso de las características físicas, económicas y sociales del país. Se requerían cartas topográficas, planos, censos y todo tipo de estadística que proporcionara los conocimientos indispensables para elaborar una división aplicable a la realidad chilena. Se reveló así la precariedad económica del Estado, pues se expuso el problema del financiamiento con el que debía solventarse un programa de magnitud como el que significaba la transformación del espacio, su organización interior y la gestión del sector público a lo largo del país. Los costos que implicaba el proyecto no solo guardaban relación con la realización y puesta en práctica de la división político-administrativa, sino también con su subsistencia, sobre todo en un período de gestación del Estado que se caracterizó por la búsqueda del orden y la estabilidad política. El organismo optó por no precipitarse a instaurar una división definitiva y, en su defecto, envió un mensaje el 15 de septiembre de 1823 con un proyecto de ley, según el cual "el Estado se subdividirá en provincias, cuya demarcación conveniente resulte del exacto conocimiento de sus terrenos, producciones y población"73.

El hecho de presentar un proyecto que no establecía ninguna división, sino que solo manifestaba la intención de fraccionar el país en un futuro próximo, revela la experiencia adquirida a raíz de los sucesos pasados, en la medida en que los dirigentes nacionales no se precipitaron en instaurar una ordenanza que no permitiese su posterior modificación, aunque finalmente esto haya jugado en contra de una resolución rápida. La discusión del proyecto de ley se prorrogó en las siguien-

72 El documento se firmó el 15 de septiembre de 1823 por Joaquín Larraín, Isidro Pineda, José Miguel Irarrázabal, Francisco B. Fontecilla y José María Silva. SCL, tomo VIII, sesión del 17 de septiembre de 1823

73 Idem. 
tes sesiones del Congreso, hasta que los constituyentes solo acordaron dividir el Estado en un mayor número de departamentos, sin dar cuenta de los planes anteriores. Autorizaron al Ejecutivo para formar una nueva demarcación, considerando todos los conocimientos necesarios para ello, y con el deber de presentarla a la legislatura del momento ${ }^{74}$.

\section{Nuevos ELEMENTOS EN EL DEBATE}

La discusión sobre una división político-administrativa definitiva para la república se suspendió debido a que los constituyentes tenían sus miras puestas en la elaboración de un nuevo código fundamental. La discusión se renovó solo después de haberse promulgado la nueva Constitución, en diciembre de 1823, la que tampoco estableció la cantidad de provincias del territorio nacional, porque solo enunció que "el Estado se divide gradualmente en gobiernos departamentales, delegaciones, subdelegaciones, prefecturas e inspecciones" 75 . El asunto quedó así en un relativo suspenso durante el año 1824, ya que se acentuó la inestabilidad política, tanto por la derogación del reglamento constitucional como por el rechazo de las provincias al gobierno central, sustrayendo a sus representantes del legislativo en $1825^{76}$. Ante la ausencia de un Congreso que representase a todas las zonas del país, las provincias recurrieron a la formación de gobiernos particulares instituidos bajo la dirección de asambleas, por lo que entre 1823 y 1826 la administración del país quedó fraccionada en diversos cuerpos representativos. Muestra del vacío de poder existente en la época.

El debate se reanudó a comienzos de 1825. En enero José Miguel Infante propuso que se ejecutara el plan del legislativo de 11 de junio de 1823, que dividía el territorio de la república en ocho provincias, lo que condujo a ásperas rencillas con el Poder Ejecutivo. La petición no generó repercusiones sino hasta el 20 de octubre, cuando el Director Supremo, bajo la consigna de mejorar la administración pública y contribuir al progreso del país, envió a las asambleas de Concepción y Coquimbo una copia de los documentos relativos al proyecto, esperando su aprobación. Presentó además algunas variaciones, que se relacionaron con cambiar la denominación de departamentos a provincias, variar el título de gobernadores intendentes a simplemente gobernadores, y hacer modificaciones de los límites. Planteó cambiar el deslinde que separaba la quinta de la sexta provincia y el límite meridional de la primera, respetando en ambos el principio de demarcaciones naturales. Propuso que la provincia de Coquimbo quedase comprendida entre el despoblado de Atacama y el río Choapa, a diferencia del antiguo plan del Senado, que establecía como límite sur la Quebrada del Negro.

74 El documento se redactó y firmó el 9 de octubre de 1823. SCL, tomo VIII, sesión del 6 de octubre de 1823 .

75 Valencia, op. cit., tomo I, 139.

76 Collier, op. cit., 247, 248 y 269. 
Planteó que la quinta provincia se circunscribiera a la zona comprendida entre el río Maule y el Diguillín, continuando su curso por el Itata hasta llegar al mar. De este modo la sexta provincia abarcaría el territorio entre dicha demarcación y el límite con la jurisdicción de Valdivia, quedando así más proporcionada que antes en cuanto a territorio y población 77 .

En su mensaje, Freire llamó nuevamente a utilizar los accidentes naturales en la demarcación interna, y apeló a las ideas de equidad y proporcionalidad de las provincias al afirmar:

\footnotetext{
“¿no sería una quimera pensar en federación entre solo tres provincias y tan desiguales como ellas existen hoy? ¿No sería también igualmente alarmante, no excitaría los celos y quejas y levantaría un obstáculo insuperable a la reconciliación general de todos los pueblos de la república al ver, v. gr., que la provincia de Santiago se subdivida y que la de Concepción se resistiese a hacerlo?"78.
}

En vista de las hostilidades mantenidas en 1823 y 1824, se aludió al principio de proporcionalidad en la noción de que también tenía un fin conciliador. La demarcación y división del territorio constituía así una herramienta esencial, que colaboraba con la conservación del orden y la tranquilidad del país, tan anhelados en aquellos años de inestabilidad política. La división, tanto bajo un sistema unitario como federal, constituía un "gran paso, que debe producir el adelantamiento más rápido en toda la república, al mismo tiempo que será el garante más seguro de la conservación del orden y tranquilidad en lo sucesivo"79.

Las provincias de Concepción y Coquimbo respondieron tempranamente al comunicado mediante un mensaje firmado el 29 de octubre de 1825 , la primera, y el 5 de noviembre la segunda. Ambas estuvieron de acuerdo con aprobar el plan del Senado de 1823, pero hicieron observaciones sobre las modificaciones planteadas por el gobierno. La Asamblea de Concepción aceptó aumentar el número de jurisdicciones por razones de conveniencia pública, pero expresó sus propias reformas y fundamentos. Sostuvo que debía cambiarse el límite que separaba el quinto del sexto departamento por el del río Nuble continuando por el Itata hasta el mar, porque era más ventajosa para ambas circunscripciones. El quinto departamento incorporaba las delegaciones de Linares, Parral, San Carlos, Cauquenes y Quirihue, "partidos de vasta extensión y de una feracidad privilegiada; sus terrenos disponen comodidad para toda clase de crianzas y para la industria agraria; parte son quebrados y otros llanos; las haciendas, pingues; sus propietarios, ricos; puertos de mar y secos, ya es visto que las tiene" 80 . Sus representantes también sostuvieron que según la antigua demarcación, el sexto departamento no reunía estas favorables condiciones, debido a que sus tierras eran mayormente irregulares $\mathrm{y}$, por ende, poco aprovechables, y carecían de grandes propietarios

\footnotetext{
77 SCL, tomo XII, sesión del 27 de julio de 1826.

78 Idem.

79 Idem.

80 Idem.
} 
que aventajaran su situación. Así, la Asamblea declaró que entre los territorios que comprendía su jurisdicción, solo Chillán y Los Ángeles tenían las tierras más fértiles, existiendo un balance exageradamente desproporcionado entre ambos departamentos.

“¿Quién que haya visto a Coelemu no confiesa su esterilidad y porción de terreno inútil e incapaz de hacerlo fructificar? ¿Quién que mire a Rere no ve quebradas inaccesibles y barrancas, cuya abundancia y grandor inutilizan muchas partes de las haciendas? ¿Quién no asegura que, si al departamento de Concepción se le separa Chillán, no debe contar con más terreno plano que el de Los Ángeles? La Asamblea sabe muy bien que los deslindes no son una barrera para las relaciones de unas y otras provincias; pero observa que a cada territorio se le debe dar cuanto necesite para su comodidad, industria y adelantamiento. Se advierte que, en los últimos cinco partidos, es decir, en Los Ángeles, Rere, Puchacai, Lautaro y Coelemu, no hay grandes propietarios; sus fortunas no pasan de medianas en unos y de escasas en los mas; en conclusión, sin Chillán queda miserable el departamento de Concepción, y jamás podrá consolarle una esperanza, que, aunque probable, no es segura, y en todo caso, muy remota.

Si la línea se tira por el Diguillín, entrando en Itata hasta el mar, como propone el gobierno $[\ldots]$, le obstan las reflexiones que antes se han manifestado; queda entonces el departamento de Concepción sin Chillán, reducido a Los Ángeles (disminuido grandemente en sus brazos y exterminado en sus fortunas, sin población ni habitaciones por ahora, todo desierto y abandonado), a Rere, Puchacai, Lautaro y Coelemu, cuya descripción territorial y demás calidades no pueden hacer jamás por sí solas una provincia que no sea menesterosa" 81 .

La Asamblea de Concepción mencionó otras desventajas de la delimitación por el Diguillín, planteada por el gobierno. Esta demarcación cortaba por la mitad a la delegación de Chillán, mientras que la que corría por el Nuble respetaba sus linderos tradicionales. Si Chillán quedaba en el quinto departamento, se generarían conflictos de interés al disputarse la capital provincial con Cauquenes, la que aspiraba, por derecho o por situación geográfica, a erigirse como cabecera de la región. Asimismo, Chillán debía quedar bajo el mando civil y militar de la provincia de Concepción, por su vulnerabilidad ante invasiones indígenas por el oriente. A pesar de dichas discrepancias, los representantes penquistas se mostraron abiertos con respecto a otros temas, como cambiar la denominación a provincias en vez de departamentos, aunque sobre el apelativo particular de cada jurisdicción, retomó una postergada idea de otorgarles los nombres de ilustres ciudadanos muertos en defensa de la patria, lo que pretendía inmortalizar a los héroes de la república y dar con ello un ejemplo a las futuras generaciones, manteniendo vivo el recuerdo de la lucha por la libertad. Los antecedentes de esta intención se remontan a junio de 1823, cuando el Senado Conservador acordó pedir al gobierno un acta de los personajes que se distinguieron en la causa independentista junto a su lugar de nacimiento, con el fin de utilizar este criterio en la nominación de los entonces

\footnotetext{
81 Idem.
} 
departamentos. El Director Supremo acogió la petición, pero no se presentó un proyecto concreto y, por lo tanto, la medida no se ejecutó ${ }^{82}$.

La relevancia de esta particularidad nominativa radica en la advertencia hecha por la misma Asamblea de Concepción. En caso de ser acogida la propuesta, sugirió proceder con especial precaución en escoger a los mencionados "héroes", ya que podía abrirse un espacio a nuevas animadversiones que obstaculizaran la unidad del país. Manifestó entonces que "siempre sería preciso gran cuidado para evitar celos infundados" 83 . En correlación con el caso francés, Mona Ozouf sostiene que al momento de elegir los nombres de los departamentos, la Asamblea "opta por lo menos arbitrario: los mares, las montañas, los ríos, o la posición geográfica, sirven para bautizar las nuevas circunscripciones", haciendo que la realidad geográfica nuevamente se imponga frente al problema del ordenamiento territorial ${ }^{84}$.

El mensaje de Concepción retomó además otros aspectos en los que confluían problemas de financiamiento, rivalidades, celos, pretensiones e intereses locales. En vista de los recursos que se debían invertir para el nuevo ordenamiento del territorio, aseguró que no era posible practicar el proyecto en las circunstancias en que se encontraba el país. Chile no estaba en condiciones de incurrir en los gastos que significaba aumentar el número de las provincias, porque había que contemplar tanto la creación como el mantenimiento de las nuevas entidades para lograr la estabilidad y una beneficiosa administración, lo que se traducía en un gran desembolso de capital destinado al pago de instituciones públicas y su corespondiente personal administrativo. Los representantes de Concepción así lo señalaron en 1825:

“por más que la Asamblea está convencida de que el plan de la demarcación debe ser el indicado, observa que por ahora no es dable plantearlo. Las innovaciones locales, las pretensiones de los pueblos, los agravios, las rivalidades consiguientes, todo, todo crecería en razón directa de hallarnos en tiempos de efervescencia y de partidos.

[...] Chile no se halla en estado de ocurrir a estos gastos, cuando ni tiene para los actuales. El buen orden y los principios de economía y de política dictan proporcionar los gastos a las entradas. Crear establecimientos, para no poderlos mantener, a mas de ser un descrédito público, hace o aumenta el atraso y miseria del país, en vez de engrandecerlo" 85 .

Por su parte, la provincia de Coquimbo firmó, el 5 de noviembre en La Serena, su respuesta al comunicado del Director Supremo. Sus representantes reconocieron también la importancia de ejecutar el fraccionamiento de la república debido a las amplias ventajas que proporcionaría, afirmando que

82 La constancia de estos hechos se plasmó en los comunicados de ambos poderes, firmado el primero el 18 de junio y el segundo el 4 de julio de 1823 . Véase $S C L$, tomo VII, sesiones del 11 de junio y 4 de julio de 1823 y $S C L$, tomo XII, sesión del 27 de julio de 1826.

83 Idem.

84 Furet y Ozouf, op. cit., 453.

85 SCL, tomo XII, sesión del 27 de julio de 1826. 
“el asunto exige por sí mismo las más serias y detenidas consideraciones; empero, las utilidades que va a reportar al Estado, bajo cualquier aspecto que se mire la ejecución de un plan de suma importancia, suspirado tanto tiempo por los hombres pensadores, nos dispensa de entrar en su análisis, contentos de que la opinión general se haya pronunciado eficazmente en su favor. Esta Corporación se cubrirá de gloria si, con su asentimiento, a una empresa tan laudable, puede cooperar a la regeneración del Estado, y asegurar las bases de su dicha perdurable" $"$.

En cuanto a las reformas planteadas por el gobierno, la Asamblea manifestó sus apreciaciones en los asuntos que tenían directa relación con sus intereses, como los límites de su provincia. Contraria al plan del Director Supremo, declaró que su deslinde meridional debía estar en la Quebrada del Negro y no en el río Choapa, aludiendo a las particulares características físicas de la región. Si se ejecutaba la propuesta del gobierno, Coquimbo perdería las mejores tierras de su jurisdicción, "quizás la más feraz de toda su superficie, de la mejor calidad y en el ramo más esencial para el fomento de nuestra abatida industria; pierde también una población de más de dos mil vecinos útiles para la labranza”. Además, sacrificaría el puerto de Conchalí, que debía facilitarle a Illapel la exportación de sus productos, y que ante el cambio debería recurrir al puerto de Coquimbo, considerado "distante muchas leguas y por caminos fragosos y enteramente desprovistos". En torno al cambio en la denominación de las provincias, Coquimbo sostuvo que no afectaría al cumplimiento de sus garantías, pero que la tradición, esa "costumbre inmemorial", ejercía un gran peso, incentivando que las nuevas jurisdicciones tomasen el nombre de sus respectivas capitales, como se había acostumbrado hacer hasta el momento. A pesar de estas observaciones, la Asamblea de Coquimbo declaró estar decidida a renunciar a sus pretensiones con el fin de lograr la tan anhelada organización del Estado 87 .

En los tres comunicados de las provincias de Santiago, Coquimbo y Concepción se expusieron temas que habían sido materia de discusión y que encontraron acuerdo entre los políticos nacionales. Los puntos de conciliación convergieron en los diversos beneficios que aportaría al país la nueva división político-administrativa. La creencia en el progreso de las localidades fue recurrente para fundamentar cualquier reforma que se hiciese a las demarcaciones de las provincias. Asimismo, las ideas de igualdad y proporcionalidad se plasmaron en el territorio chileno al discutirse fervientemente que aquellos eran los principios por los cuales debía regirse cualquier división territorial. Los tres mensajes también resaltaron la proporcionalidad de los recursos. De nada servía a una provincia tener amplios terrenos si estos eran improductivos o si no tenían las herramientas para generar los recursos necesarios para progresar. Las provincias buscaron constantemente sustentarse a sí mismas en un mínimo grado, con el objeto de no depender únicamente del gobierno central. Por lo demás, ambas asambleas elaboraron sus informes en base a lo que las afectaba directamente, por lo que mostraron modificaciones con-

\footnotetext{
86 Idem.

87 Idem.
} 
cretas y fundamentadas en torno a sus propias delimitaciones. Aunque es natural que cada una velara por sus intereses particulares, resulta interesante que no se manifestaran de forma alguna sobre las otras provincias del Estado o la unidad del proyecto. Entre los factores que influyeron en este comportamiento, encontramos la ignorancia de los representantes provinciales acerca de las condiciones geográficas, económicas, financieras, demográficas y culturales de las otras provincias, así como una preferencia práctica por referirse solo a los asuntos de su jurisdicción, debido a la mayor cercanía y conocimiento que podían tener al respecto. Predominó así una tendencia regionalista antes que nacional, pues no se estudiaron los proyectos de división de forma global, en función de cómo afectaría cada plan de demarcación a toda la república, y las provincias buscaron reivindicar sus derechos particulares en desmedro de la perspectiva nacional.

Este problema adquiere más coherencia cuando se inserta en el contexto de que el país había recurrido a las asambleas como forma de representación activa de las provincias. Estas plantearon sus intereses y reparos hacia el gobierno a través de estos cuerpos, haciendo ver sus impresiones sobre los diversos proyectos de división del territorio. El asambleísmo de la época contribuyó a la inestabilidad y desorganización del Estado, pues ante cualquier roce con el Ejecutivo, las circunscripciones desconocían al gobierno central quitando a sus representantes del legislativo $^{88}$. Esta actitud influyó directamente en la continua postergación que sufrió la división político-administrativa de la república, pues entre 1823 y 1826 no hubo una organización del territorio estable ni permanente. Sin embargo, en este contexto de reorganización del Estado, se elaboró el Reglamento Provisorio para la Administración de las Provincias del 30 de noviembre de 1825, el cual fue presentado al Consejo Directorial, representante del Poder Ejecutivo ${ }^{89}$. Gracias a la ausencia de un Congreso Nacional que representara a todas las provincias, y debido a las consecuentes atribuciones legislativas y ejecutivas de las asambleas, dicho código pretendía regular la administración provincial ${ }^{90}$. Este abordó la formación, las

88 Véase Heise González, op. cit., capítulo II, "Limitación municipal de la conciencia política", 61-65.

89 El 12 de noviembre de 1825, Ramón Freire instaló un Consejo Directorial, para que gobernase el país mientas él realizaba la expedición que pretendía expulsar las últimas fuerzas realistas de Chiloé. El Consejo se compuso por José Miguel Infante, presidente, Joaquín Campino, ministro del Interior y de Relaciones Exteriores, José María Novoa, en la cartera de Guerra y Marina, y José Manuel Gandarillas, en el Ministerio de Hacienda. Sin embargo, la corporación presentó tres variaciones en su composición durante su vigencia. Ejerció sus funciones entre el 15 de noviembre de 1825 y el 7 de marzo de 1826, fecha en que Freire reasumió como Director Supremo de la República. En Valencia Avaria, op. cit., tomo I, 455 y 456.

90 Debido a la derogación de la Constitución política de 1823 , se formó un Congreso Nacional con fines de elaborar un nuevo reglamento constitucional en noviembre de 1824 . Sin embargo, el 20 de abril de 1825, antes de haber confeccionado el código, la provincia de Concepción retiró a sus diputados del Cuerpo Legislativo y estableció una Asamblea Provincial. El Director Supremo disolvió el Congreso el 17 de mayo y la provincia de Coquimbo, por su parte, siguiendo los pasos de la provincia del sur, instauró su propia asamblea. Ante esta situación, Santiago se reunió bajo la misma institución local el 15 de junio. Al mes siguiente, el general Freire convocó a la formación de un nuevo Congreso Nacional, pero solo la provincia de Santiago envió a sus representantes. A pesar de esto, el Legislativo comenzó a sesionar en septiembre de aquel año, pero sin carácter nacional, ya que solo era representativo de la provincia capitalina. Véase Collier, op. cit., 269. 
atribuciones y restricciones de las asambleas provinciales, sobre los gobernadores, las municipalidades y la administración de justicia. Asimismo, se refirió a la división de la república, medida absolutamente necesaria para la organización de las instituciones administrativas mencionadas. La demarcación de los deslindes provinciales tuvo íntima relación con el espíritu democrático reflejado en la representación nacional, en este caso, las asambleas. El reglamento estableció que los jueces de letras y las asambleas debían reunirse en las capitales de cada unidad administrativa, por lo cual se requería que ambas estuviesen bien definidas y delimitadas para no provocar disputas entre pueblos y ciudades de una misma circunscripción, quienes competirían por erigirse como cabeceras de su provincia. No obstante, por ser un documento provisorio -no fue sancionado ni promulgado-, la división político-administrativa también tuvo un carácter temporal, al manifestar que se esperaría la sanción de una legislatura nacional. De este modo, el reglamento propuso la siguiente la división del Estado:

“ARTÍCULO PRIMERO. La República se divide en provincias, municipalidades y parroquias. ART. $2^{\circ}$.- El número, nombre y límites de las provincias de la República será, por ahora, y hasta la sanción de la primera Legislatura Nacional en la forma siguiente:

Primera provincia.- Desde el despoblado de Atacama hasta la orilla norte del río Choapa. Esta provincia se denominará Coquimbo; su capital, la ciudad de la Serena.

Segunda provincia.- Desde la orilla sur del río Choapa hasta la cuesta de Chacabuco, y su cordón de montañas hasta el mar. Esta provincia se denominará Aconcagua; su capital, la ciudad de San Felipe.

Tercera provincia.- Desde Chacabuco hasta la orilla norte del río Cachapoal. Esta provincia se denominará Santiago; su capital, la ciudad de este nombre.

Cuarta provincia.- Desde la orilla sur del río Cachapoal hasta la orilla norte del Maule. Esta provincia se denominará Colchagua; su capital, la villa de Curicó.

Quinta provincia.- Desde la orilla sur del río Maule hasta el río Nuble, en su nacimiento de la Cordillera, siguiendo su curso hasta la confluencia con el Itata, y desde aquí de este río hasta su desembocadura en el mar. Esta provincia se denominará Maule; su capital, la villa de Cauquenes.

Sexta provincia.- Desde los límites indicados al anterior, hasta lo que hoy reconoce con el gobierno de Valdivia. Esta provincia se denominará Concepción; su capital, la ciudad de este nombre.

Sétima provincia.- Todo el territorio que hoy se reconoce bajo la dirección del gobierno de Valdivia. Esta provincia se denominará Valdivia; su capital, la ciudad del mismo nombre.

Octava provincia.- El archipiélago de Chiloé. Esta provincia conservará su mismo nombre; su capital, la ciudad de Castro.

ART. $3^{\circ}$.- Los jefes de dichas provincias se titularán simplemente gobernadores de ellas. ART. $4^{\circ}$.- El gobernador de cada provincia deberá acordar con los gobernadores de las provincias vecinas al Sur y Norte sobre aquellos puntos de límites acerca de lo que pueda ocurrir alguna duda, después de la asignación que queda hecha en el presente decreto, dirigiendo sus informes sobre el particular al Congreso Nacional, o bien, a la corporación o magistratura que posteriormente se designare" 91 .

91 SCL, tomo XII, sesión del 27 de julio de 1826. 
Por la vía de sus asambleas, el reglamento otorgó a las provincias amplias facultades y gran libertad de acción en cuanto a su gobierno interior. Ejemplo de ello fue la autorización concedida a los gobernadores provinciales para modificar las demarcaciones de su jurisdicción, siempre que presentaran sus peticiones al Congreso Nacional o a la magistratura correspondiente. De la misma forma, el artículo 12, sobre las atribuciones de las asambleas provinciales, estableció que estas tenían la facultad de "hacer la división de la provincia, conforme a las bases que quedan aquí indicadas"92. No obstante, la discusión suscitada en 1825 giró solamente en torno al comunicado emitido por el Director Supremo y a las respuestas de las provincias existentes, sin dar pie a mayores consideraciones ni debates.

\section{EL AVANCE FEDERAL}

La dirección que tomó el proceso en 1826 tuvo un significado político concreto que venía generándose desde 1823. El federalismo irrumpió en Chile con gran efervescencia en los años 1825 y 1826, incorporándose en el debate sobre el ordenamiento administrativo del Estado. Si bien desde hacía tiempo los políticos chilenos manifestaban la importancia que tenía fijar la división del territorio nacional y la demarcación de las provincias para el desenvolvimiento de la nación, hacia los años 1825 y 1826 esta idea llegó a ser esencial e indispensable, debido al régimen político que se quiso instaurar. Para implantar el federalismo en Chile, la división del espacio constituía un elemento base sobre el cual debía construirse dicho sistema.

Hacia 1826 las ideas federales comenzaron a tener verdadero peso político entre las provincias. La gran influencia que ejercían los regímenes federales americanos, como México y los Estados Unidos, hizo que cualquier indicio de progreso de ambas naciones se atribuyera al federalismo y a su respectiva división políticoadministrativa. Sin embargo, la idea de dividir el espacio en una multiplicidad de unidades administrativas de menor extensión no provino solo del modelo norteamericano. Más bien, dicho ejemplo tuvo mayor significación en Chile dentro de un contexto de ansias descentralizadoras, que tendió a confundirse, equívocamente, con el sistema federal.

Las circunstancias en que se encontraba el país en los inicios de 1826 ayudaron a que las ideas federales alcanzaran su punto cúlmine aquel año. La ausencia de Ramón Freire del gobierno hizo que se delegara el Poder Ejecutivo en un Consejo Directorial, cuyo principal mandatario fuera el máximo exponente del federalismo en Chile, José Miguel Infante. Dicho aspecto contribuyó a que estas ideas fueran puestas sobre el tapete de la discusión política e incentivó su promoción entre los legisladores, de manera que fue en este período cuando el federalismo obtuvo sanción a través de normas que pretendieron organizar el país bajo un régimen federal, entre ellas, la promulgación de la primera división político-administrativa republicana ${ }^{93}$.

92 "Proyecto de un reglamento provisorio para la administración de las provincias, presentado al Consejo Directorial por el Ministro del Interior, en 30 de noviembre de 1825 ", en Idem.

93 Véase Heise González, op. cit., 170-178. 
Los roces interprovinciales contribuyeron a generar el ambiente para la aceptación generalizada del federalismo, en la medida que este proporcionaba a las provincias mayor libertad y autonomía frente al gobierno central ${ }^{94}$. En este escenario, José Miguel Infante expresó, en el momento de firmar el decreto que instauraba el federalismo en la república, que "este es el día en que empiezan a temblar los tiranos, y los hombres libres a llenarse de contento al oír Federación"95. Para otros legisladores, como el senador Lazo, el paso significaba, como afirmó en julio de 1826,

"un antemural contra la opresión y la mejor garantía de la libertad de los pueblos. ¿No hacen trescientos años que Chile está bajo el sistema unitario, primero bajo la dominación de un déspota, y después bajo el gobierno patrio? ¿Cuáles son las ventajas que hemos notado? ¿Cuáles las mejoras y derechos que han obtenido los pueblos?"96.

Las aspiraciones de libertad y democracia, que aquí se muestran de forma evidente, hicieron que se pensara en dividir el territorio en secciones de menor extensión para lograr mayor transparencia y una efectiva fiscalización de las autoridades regionales, lo que repercutió en que las provincias buscaran un sistema de administración interna a través de la elección directa de cuerpos representativos, como las asambleas provinciales. A diferencia del federalismo norteamericano, el chileno constituía una herramienta descentralizadora con miras a la autonomía provincial $^{97}$. El mayor fraccionamiento del espacio se convertía así en una medida fundamental, que permitía reorganizar el territorio según un modelo moderno de administración, desligándolo de la antigua gestión colonial al, también, circunscribir a los ciudadanos en jurisdicciones geográficamente delineadas con fines de representación nacional.

El debate sobre el ordenamiento político-administrativo se retomó en 1826, cuando el Consejo Directorial decretó de forma provisoria un nuevo plan de demarcación, el 31 de enero de 1826, encontrándose la concordancia entre el gobierno y los legisladores que en tantas ocasiones discreparon sobre el tema. La nueva división debía esperar la reunión de la Legislatura Nacional para su sanción y presentó las mismas características, artículos y delimitación que el Proyecto de Reglamento provisorio para la administración de las provincias de 1825 , reafirmando la facultad de los gobernadores provinciales para intervenir en sus fronteras jurisdiccionales. Con todo, su aprobación constituyó un punto significativo en la evolución del proceso. Así lo planteó Ramón Freire en un mensaje al Congreso Constituyente el 4 de julio de 1826, cuando, aludiendo a que la medida pondría fin a las rivalidades interprovinciales, afirmó

94 Temáticas como el anhelo de libertad, el fervor democrático y el localismo en relación con la supremacía ejercida por el gobierno central durante el período en Chile, fueron analizadas por Julio Heise. Véase Ibid., 166, 168 y 169, y Jaime Etchepare Jensen, "El Federalismo, antecedentes, características: su fugaz vigencia en Chile, 1823-1830; perspectivas futuras", en Revista Libertador O'Higgins, $\mathrm{N}^{\circ} 13$, Santiago, 1996, 72.

95 Citado por Etchepare Jensen, op. cit., 73.

96 SCL, tomo XII, sesión del 11 de Julio de 1826.

97 Etchepare Jensen, op. cit., 75. 
"podrá en lo sucesivo producir bienes incalculables, no solamente por el incremento que deben tomar los diferentes ramos de industria, que se fían al cuidado e interés locales, sino porque apagará el fuego de los celos y rivalidades recíprocas de los pueblos, dando a nuestras instituciones un carácter de firmeza y solidez que hasta ahora no han tenido, con riesgo del orden interior y con mengua de nuestro crédito"98.

El decreto que implantaba la división de la república, el 31 de enero de 1826, estableció:

"Convencido el gobierno de la necesidad de dividir el territorio de la república en un mayor número de provincias, y satisfecho de la persuasión general de todos los chilenos, por la justicia y conveniencia de esta medida, habiendo considerado con la más detenida meditación sobre el mejor modo de verificarlo, en el que pudiesen conciliarse los intereses y ventajas de todas las provincias, procurando evitar no solo los perjuicios reales, sino hasta los pretextos de quejas o reclamaciones que la aprensión de antiguos celos o rivalidades pudiesen sugerir y habiendo tomado sobre el particular, informes de las personas y corporaciones mas imparciales, y del más conocido e ilustrado patriotismo, ha venido en decretar la división del territorio en la forma siguiente:

ARTícUlo PRIMERO.- Por ahora y hasta sanción de la Legislatura Nacional, el territorio de la república se divide en las ocho provincias siguientes:

Primera provincia.- Desde el despoblado de Atacama, hasta la orilla norte del río Choapa. Esta provincia se denominará la provincia de Coquimbo; su capital, la ciudad de la Serena.

Segunda provincia.- Desde la orilla sur del río Choapa hasta la cuesta de Chacabuco y su cordón de montañas hasta el mar. Esta provincia se denominará la provincia de Aconcagua; su capital, la ciudad de San Felipe.

Tercera provincia.- Desde Chacabuco hasta la orilla norte del río Cachapoal. Esta provincia se denominará la provincia de Santiago; su capital, la ciudad de este nombre.

Cuarta provincia.- Desde la orilla sur del río Cachapoal hasta el río Maule. Esta provincia se denominará la provincia de Colchagua; su capital, la villa de Curicó.

Quinta provincia.- Desde la orilla sur del río Maule hasta el río Ñuble en su nacimiento de la Cordillera, siguiendo su curso hasta la confluencia con el Itata, y desde aquí el de este río hasta su embocadura en el mar. Esta provincia se denominará la provincia de Maule; su capital, la villa de Cauquenes.

Sexta provincia.- Desde los límites indicados a la anterior hasta los que hoy reconoce con el gobierno de Valdivia. Esta provincia se denominará la provincia de Concepción; su capital, la ciudad de este nombre.

Sétima provincia.- Todo el territorio que hoy se reconoce bajo la dirección del gobierno de Valdivia. Esta provincia se denominará la provincia de Valdivia; su capital, la ciudad de este nombre.

Octava provincia.- El archipiélago de Chiloé. Esta provincia conservará su mismo nombre; su capital, la ciudad de Castro.

ART. $2^{\circ}$.- El gobernador de cada provincia deberá acordar con los gobernadores de las provincias vecinas al Sur y Norte sobre aquellos puntos de límites acerca de los que pueda ocurrir alguna duda, después de la asignación que queda hecha en el presente

98 SCL, tomo XII, sesión del 4 de julio de 1826. 
decreto, dirigiendo sus informes sobre el particular al Gobierno Nacional, o bien a la corporación o magistratura que posteriormente se designare.

ART. $3^{\circ}$.- Todo lo urgente relativo a la organización y administración de las nuevas provincias se determinará por el Gobierno provisoriamente hasta la reunión de la primera Legislatura Nacional" 99 .

Debido a que la división decretada debía ser sancionada por la Legislatura Nacional, el 11 de julio Juan de Dios Romero propuso una moción a la Comisión de Constitución para cumplir con dicho trámite. En ella expuso el avance que la norma proporcionaría a las provincias, sobre todo de índole económica, sosteniendo que "sus males se minoran con la inmediación de los recursos, sus producciones adquieren la importancia que antes no tenían, y en fin, todo se vivifica y toma nuevo ser a la sombra de un Gobierno cuya esencia debe ser el obrar y producir el bien" 100 .

Durante la sesión del 13 de julio se discutió sobre la elección de los gobernadores provinciales por las asambleas, haciéndose visible el papel que cumplía la división político-administrativa en la representación nacional. Los legisladores hicieron hincapié en su relación con el tema del sufragio y el nombramiento de los gobernadores, ya que el no saber cuántas jurisdicciones constituían el territorio del Estado, impedía conocer la cantidad de autoridades que manejaría la administración provincial. El número de circunscripciones, como la identificación de sus deslindes, permitirían conocer y ordenar a sus votantes, partidos, pueblos y ciudades. Si desde el comienzo de su vida independiente las localidades se habían organizado en asambleas compuestas por delegados de los diversos pueblos de cada provincia, al no estar demarcadas sus fronteras, no se sabía qué pueblo pertenecía a qué jurisdicción administrativa, lo que influía directamente en la conformación de dichos cuerpos representativos, tanto en el número de sus integrantes, como en su correcta representación y funcionamiento. Así, existía la posibilidad de que el representante de una determinada región, participara en más de una asamblea, o bien, que pudiera escoger sobre qué jurisdicción actuar en relación a sus intereses particulares. José Miguel Infante expuso sobre estas temáticas al decir

“¿quién no conoce que todos los gobernantes deben ser elegidos por los pueblos? Pero si todavía no se ha hecho la demarcación de las provincias, si es indudable que, faltando esta, ella no puede saberse qué número de intendentes se ha de elegir, ni en qué punto se ha de residir, ¿a qué mezclarnos en una cuestión tan delicada, y que distraería a la Sala por muchos días de la que ahora discute?"101.

A pesar de su importancia, hubo quienes simplificaron el asunto. Por ejemplo, el senador Lazo, quien manifestó

\footnotetext{
99 SCL, tomo XII, sesión del 27 de julio de 1826

100 SCL, tomo XII, sesión del 11 de julio de 1826 .

101 SCL, tomo XII, sesión del 13 de julio de 1826.
} 


\section{PROVINCIAS DE CHILE 1826}

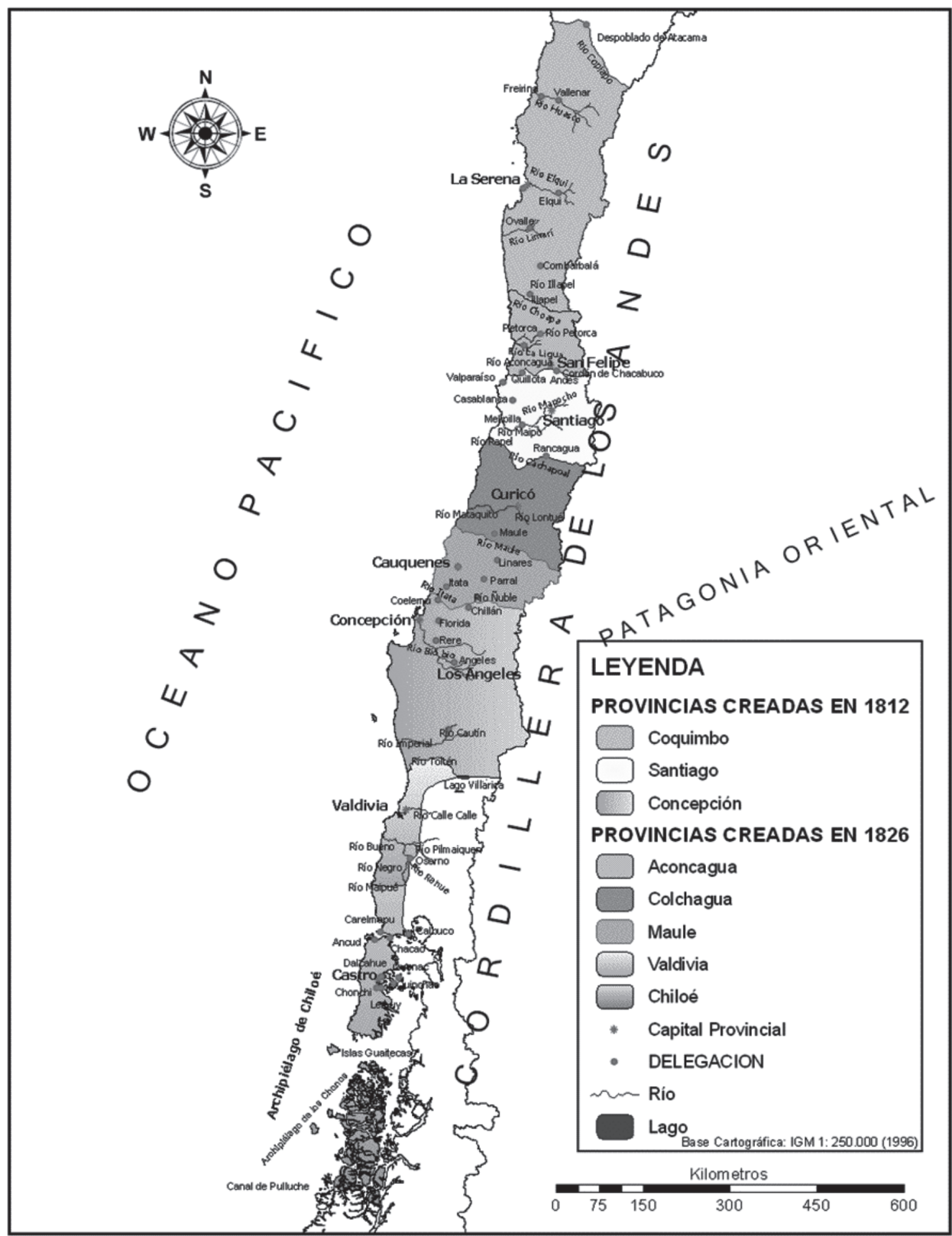

Fuente: Proyecto FONDECYT 1051034. 
“¿a qué entrar en esa demarcación de provincias? Con decir; en las provincias donde no hay intendente, que nombre cada uno de sus pueblos dos electores, y juntos en el lugar cabecera que procedan a sufragar por el intendente, así todos tienen parte en su nombramiento, y deben tenerlo, porque va a mandar sobre todos ellos; de este modo está salvado el tropiezo" 102 .

El senador Eyzaguirre subrayó la importancia de la medida, aunque no reparó en las dificultades para su aprobación cuando expresó que el problema de la demarcación "no desmerece esta solicitud, porque en cinco o seis días puede discutirse i sancionarse la nueva demarcación, i se establecería en poco tiempo una forma general para todo el Estado, tanto en los delegados que se muden como en los gobernadores-intendentes" ${ }^{103}$. Ante ello, el senador Fariñas expresó su acuerdo con José Miguel Infante, asegurando que antes de discutir sobre la elección de los gobernadores, era imprescindible determinar la división de la república, respondiendo a Eyzaguirre que

"Usía haría un servicio interesante a la Sala y al país en general (risas) si en cinco o seis días hiciese la demarcación de las provincias; estas naturalmente propenden a que la capital respectiva sea en tal o cual punto, y sus pretensiones acerca del particular no cederán tan fácilmente aunque esté en oposición la misma conveniencia nacional. No es tan fácil como se cree; la Sala misma trepidará mucho para decidirse, y así es que se demoraría mucho en determinar las provincias que deben componer la república y sus puntos capitales, lo que precisamente retardaría mucho tiempo una decisión que todos los pueblos esperan como el término de sus desgracias, y es la que actualmente se discute. [...] Solo opino de este modo porque estoy persuadido que aun no es tiempo de tratar ese punto, en virtud de lo expuesto anteriormente" 104 .

Efectivamente el problema de la división del Estado no solo incluía la demarcación interna, sino también el establecimiento de las capitales provinciales. El tema debía tratarse de forma cautelosa para no incitar rencillas posteriores, pues constituía un punto conflictivo que daría lugar a las pretensiones políticas particulares de cada localidad. Además, algunos legisladores mencionaron que a pesar de haberse decretado el nuevo ordenamiento, este no tenía el peso de una ley y, por lo tanto, debía esperar la sanción de la Legislatura Nacional. Ante esto, Fariñas afirmó que "la Comisión ha tenido presente que esa demarcación no ha tenido fuerza de ley, y que, por consiguiente las nuevas provincias deben esperar las resultas de la legislatura, sobre la demarcación de sus territorios"105. En el mismo debate se habló acerca de las consecuencias que conllevaría una posible variación en los límites internos, siendo la principal preocupación que los poblados se molestaran si se les volvía a someter a sus antiguas jurisdicciones, así como también que quedasen sin un gobernante provincial.

Hacia julio de 1826 la división político-administrativa aún no se sancionaba, por lo que José Miguel Infante lo solicitó al Congreso, el 27 de julio, la urgencia
102 Idem.
103 Idem.
104 Idem.
105 Idem. 
de erigir las asambleas y dictar una nueva Constitución, puesto que el país permanecía sin una ley fundamental desde la abolición de la Carta de 1823, administrándose solo a través de sus gobiernos locales ${ }^{106}$. Una manifestación concreta de las problemáticas suscitadas durante el 13 y 14 de julio fue que la aprobación y sanción del reglamento constitucional federal estaban reservadas a las provincias en conjunto, ya que tenían la facultad expresa para realizar dicha tarea a través de sus respectivas asambleas provinciales. El ordenamiento político-administrativo constituía el punto de partida para el funcionamiento de los mecanismos que harían posible la representación de las provincias ante el gobierno central. Fue en este escenario en que los temas concernientes al nombramiento de gobernadores y a la formación de las asambleas adquirieron gran interés e importancia, puesto que dichas instituciones, enlazadas de manera natural con el fraccionamiento del territorio, conformaron el soporte y las bases del sistema federal.

A pesar de haberse aprobado en enero de 1826 el nuevo ordenamiento políticoadministrativo, durante los meses posteriores se presentaron nuevas propuestas para modificar el plan de demarcación establecido por el gobierno. Una presentada por Salvador Bustos a la Comisión de Constitución, planteaba cambiar algunos límites internos y aumentar a nueve el número de provincias, basándose en que había "pequeñas discordancias en la demarcación de provincias que fijó el Consejo Directorial y pudiendo estas transigirse de un modo prudente que acuerde la voluntad de todos los pueblos"107. La propuesta no fue acogida por la entidad, la que solicitó que las asambleas residieran en las capitales provinciales y que se sancionara la división oficial, bajo el fundamento de que "así queda la república dividida en ocho provincias que en sí tendrán toda su respetabilidad y recursos para progresar a la par y merecer el nombre de Estados independientes y soberanos, a cuyo rango se les eleva en el sistema federal ya proclamado"108. Sin embargo, el Congreso Nacional creyó conveniente delegar a dos comisiones especiales -una para el norte y otra para el sur del país- la labor de estudiar el asunto y presentar nuevas alternativas de demarcación, aunque finalmente el esfuerzo haya sido en vano, en vista que no se consideraron sus observaciones al momento votarse el 26 de agosto de $1826^{109}$. Por 30 votos a favor y 9 en contra, los legisladores acordaron "dividir el territorio del Estado en ocho provincias, aprobar las demarcaciones de cada una de ellas, hechas por el gobierno, y las designaciones hechas por el mismo de las capitales de Coquimbo, Aconcagua y Santiago"110. Quedaba así establecido el ordenamiento del territorio, aunque de manera inconclusa, porque no se enunció la totalidad de las capitales provinciales. Con respecto a las faltantes, el 28 de agosto

106 Acompañando al comunicado, Infante presentó un proyecto de ley compuesto por once artículos en los que planteaba las bases por las cuales se erigirían las asambleas y su respectiva ubicación en las capitales provinciales. SCL, tomo XII, sesión del 27 de julio de 1826.

107 SCL, tomo XII, sesión del 11 de agosto de 1826.

108 El comunicado lo firmaron José Miguel Infante, Melchor de Santiago Concha, Francisco R. de Vicuña y Juan Fariñas. SCL, tomo XII, sesión del 17 de agosto de 1826.

109 Véase SCL, tomo XII, sesiones del 18, 21 y 23 de agosto de 1826.

$110 S C L$, tomo XII, sesión del 26 de agosto de 1826. Los nueve sufragios en contra fueron de los senadores Albano, Casiano Arce, Estanislao Arce, Bustos, Olivos, Fariñas, Lazo, José Santiago Montt y Sierra, quienes pidieron que se salvasen sus votos. Idem. 
se resolvió que la villa de Curicó fuese la capital de la provincia de Colchagua y Cauquenes la de la provincia de Maule. Las ciudades de Concepción y Valdivia se erigieron como cabeceras jurisdiccionales y Castro se fijó para la provincia de Chiloé. También se sancionaron los artículos complementarios de la división del 31 de enero, que señalaban que dicha demarcación era susceptible de mejoras. Si este llegaba a ser el caso, la siguiente legislatura nacional sería la encargada de cambiar los deslindes territoriales en concordancia con las disposiciones de la nueva Constitución. Sus capitales también podrían cambiarse, pero a través de las asambleas provinciales, una vez que estas estuviesen constituidas y hubiesen sancionado sus respectivas constituciones con la aprobación del Ejecutivo ${ }^{111}$. Con todo, el Congreso Nacional sancionó la división político-administrativa de la república el 28 de agosto de 1826, a través de los siguientes artículos:

“ARTICUlo $1^{\circ}$.- El territorio de la República se divide en las ocho provincias siguientes: PRIMERA PRovinCia.- Desde el despoblado de Atacama hasta la orilla norte del río Choapa. Esta provincia se denominará la provincia de Coquimbo; su capital, la ciudad de la Serena.

SEGUNDA PRovinCIA.- Desde la orilla sur del río Choapa hasta la cuesta de Chacabuco y su cordón de montañas hasta el mar. Esta provincia se denominará la provincia de Aconcagua; su capital, la ciudad de San Felipe.

TerCera PRovincia.- Desde Chacabuco hasta la orilla norte del río Cachapoal. Esta provincia se denominará la provincia de Santiago; su capital, la ciudad de este nombre.

CUARTA PROVINCIA.- Desde la orilla sur del río Cachapoal hasta el río Maule. Esta provincia se denominará la provincia de Colchagua; su capital, la villa de Curicó.

QUiNTA PROVINCIA.- Desde la orilla sur del río Maule hasta el río Nuble en su nacimiento de la Cordillera, siguiendo su curso hasta su confluencia con el Itata, y desde aquí el de este río hasta su embocadura en el mar. Esta provincia se denominará, la provincia del Maule; su capital, la villa de Cauquenes.

SEXTA PROVINCIA.- Desde los límites indicados a la anterior hasta los que hoy reconoce con el Gobierno de Valdivia. Esta provincia se denominará la provincia de Concepción; su capital, la ciudad de este nombre.

SÉTIMA PROVINCIA.- Todo el territorio que hoy se recorre bajo la dirección del gobierno de Valdivia. Esta provincia se denominará la provincia de Valdivia; su capital, la ciudad del mismo nombre.

Octava Provincia.- El archipiélago de Chiloé. Esta provincia conservará su mismo nombre; su capital, la ciudad de Castro.

ARTículo $2^{\circ}$.- Si la experiencia demostrase que esta demarcación no es perfecta y que es susceptible de mejoras, la siguiente Legislatura Nacional, en la forma que prevenga la Constitución, la alterará según por entonces convenga.

ARTícUlo $3^{\circ}$.- Las capitales señaladas a las provincias podrán ser variadas por sus Asambleas, cuando se hayan constituido, y sancionado sus respectivas constituciones.

ARTículo $4^{\circ}$.- Comuníquese al Supremo Poder Ejecutivo para su cumplimiento y publicación"112.

111 SCL, tomo XII, sesión del 28 de agosto de 1826.

112 Idem. 


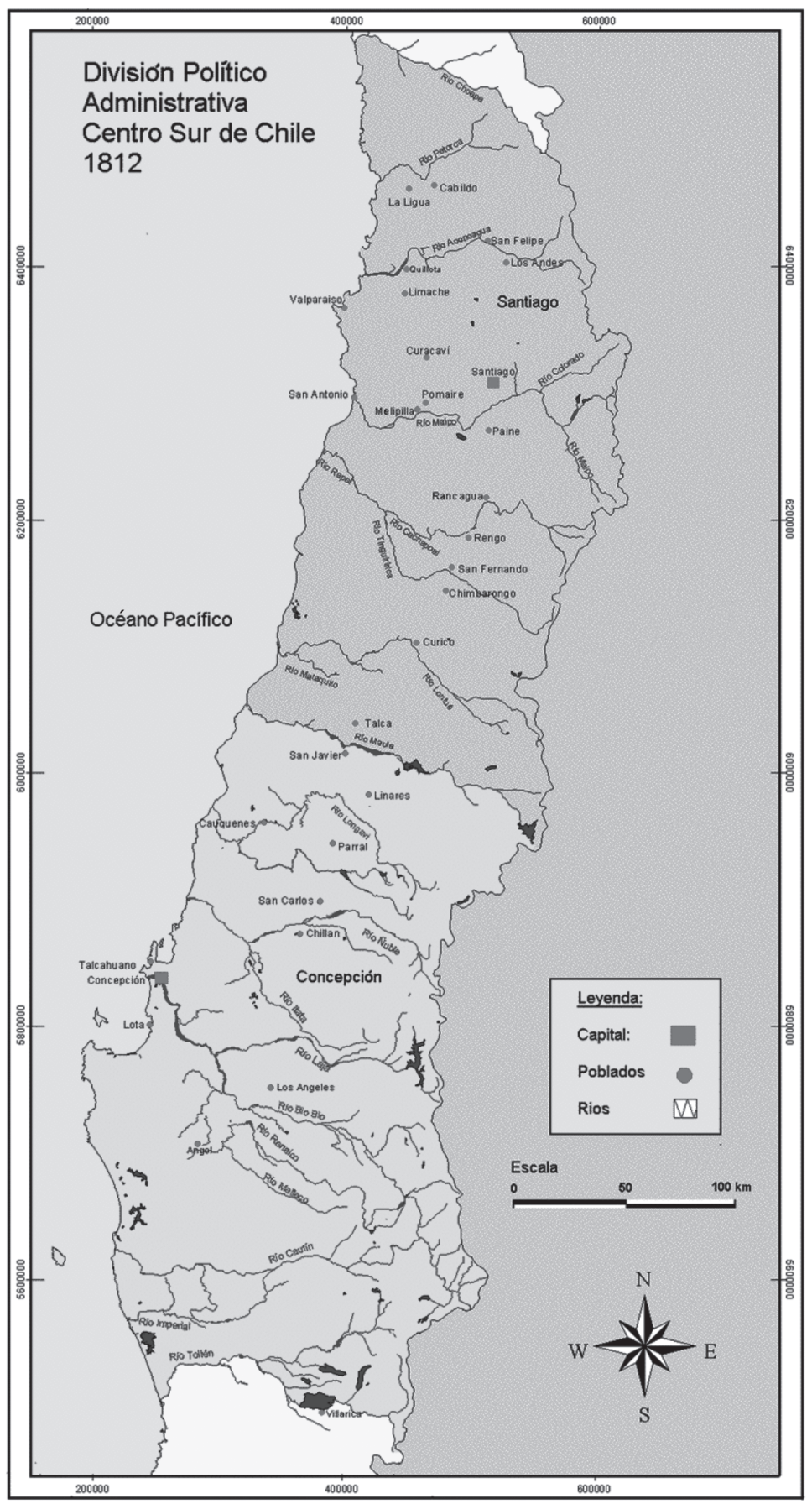

Fuente: Proyecto FONDECYT 1051034. 


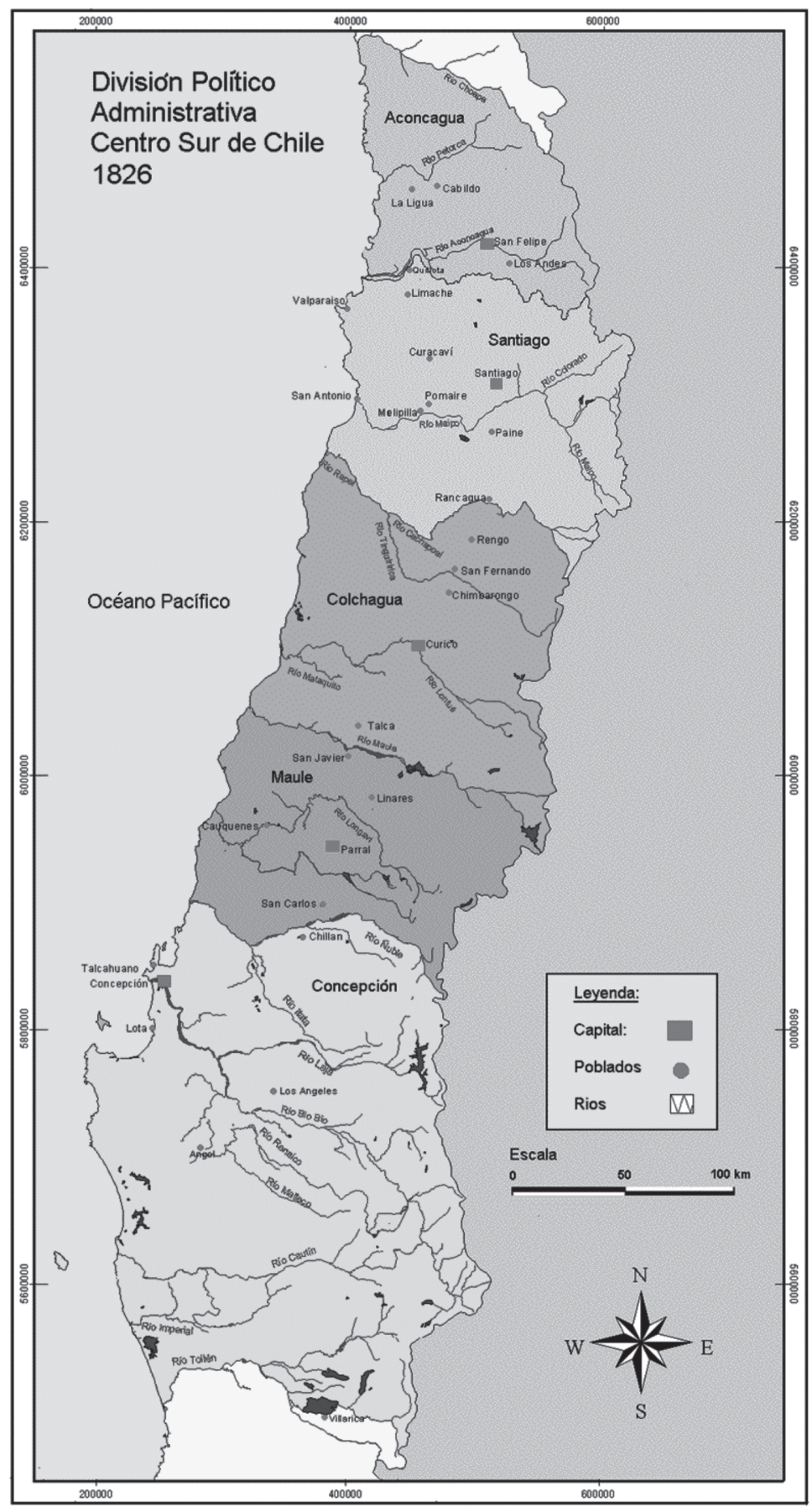

Fuente: Proyecto FONDECYT 1051034. 
Entre 1823 y 1826 se delinearon las provincias que componían el territorio nacional, poniéndose énfasis en el conjunto de elementos que las constituían, ya sea en sus límites y capitales, como en los principales requerimientos geográficos que debían tener para erigirse. Si concebimos las divisiones internas del espacio como procesos y no como hechos particulares, la sancionada en 1826 es la primera división político-administrativa de Chile porque fue la que completó el proceso de ordenamiento del territorio de la república iniciado en 1823. Sus antecedentes más directos están en las organizaciones vigentes entre 1811 y 1823 , y en el esquema de una nueva división que se discutió en marzo de este último año.

Al comparar los mapas de las provincias de 1811 y 1826 , se aprecia que esta última división político-administrativa no rechazó los deslindes antiguos. Si bien es cierto que el nuevo ordenamiento territorial cambió la fisonomía del espacio chileno al establecer un mayor número de circunscripciones, su organización incluyó los límites que separaban las antiguas tres intendencias, en la medida que constituyeron puntos legítimos por la tradición, la costumbre y la realidad geográfica. Los ríos Choapa y Maule continuaron siendo accidentes geográficos limítrofes importantes. Si el Choapa servía de línea divisoria entre las provincias de Coquimbo y Santiago antes de 1823, para 1826 se esgrimía como frontera entre las provincias de Coquimbo y Aconcagua. Lo mismo el río Maule, que según su antecedente colonial separaba a las circunscripciones de Santiago y Concepción, pero que en la nueva configuración territorial, dividía a las provincias de Colchagua y Maule. En cuestión de límites internos, por tanto, no hay ruptura en el proceso, pues más que variar las líneas de demarcación, las antiguas circunscripciones fueron fragmentando continuamente sus superficies con el paso del tiempo. La provincia de Coquimbo no tuvo variaciones, pero la que fuera la Intendencia de Santiago, en 1811, se dividió en las provincias de Aconcagua, Santiago y Colchagua, hacia 1826. Lo mismo ocurrió con la provincia de Concepción, la que se segmentó en el nuevo ordenamiento en las provincias de Maule y Concepción.

\section{INTERESES LOCALES Y CAPITALES PROVINCIALES}

La designación de capitales provinciales fue un tema postergado por los políticos chilenos durante años. A pesar de que en los primeros reglamentos constitucionales no se establecieron explícitamente las capitales provinciales, estas tuvieron correspondencia con los centros políticos y militares coloniales, es decir, Santiago y Concepción. En Coquimbo, La Serena se transformó, por iniciativa de sus vecinos, en el centro administrativo de la provincia en $1808^{113}$.

En numerosas ocasiones se mencionó que las cabeceras correspondían al punto de reunión de las asambleas, lo cual hizo que estas localidades adquirieran un estatus mayor que el de las demás ciudades dentro de cada jurisdicción. Las capitales se alzaban como los centros administrativos de cada provincia, en donde residi-

113 Cobos Noriega, op. cit., 103, 127-134. 
rían las altas autoridades provinciales, aunque esta particularidad tuvo alcances políticos al momento de presentarse la división del Estado y, más aún, con las pretensiones de establecer un régimen federal que buscaba, a todas luces, la descentralización. Erigirse como capital provincial significó así una manifestación de poder, en cuanto que se establecía un gobierno altamente desligado del gobierno central, por lo que se produjeron contrariedades motivadas por la competencia en constituirse en centro político y administrativo provincial. Así, a fines de julio y comienzos de agosto de 1826, este fenómeno se incorporó al debate sobre la división territorial del Estado, y se acentuó una vez sancionada la nueva demarcación. Producto del aumento de las unidades administrativas, surgieron demandas de diversas poblaciones para incorporarse a jurisdicciones que respondieran a sus intereses locales, así como también para conformar nuevas provincias, como respuesta a la disconformidad con las cabeceras que se les había designado.

Los problemas por la designación de capitales provinciales se concentraron principalmente en las determinaciones sobre Chillán, Valparaíso y Talca. Las solicitudes que realizó la primera para erigirse como capital de la provincia de Concepción, en octubre de 1823, y la que hizo para unirse a la provincia del Maule, en noviembre de 1826, fueron las más débiles, a pesar de haber expuesto fundamentos de corte pragmático y estratégico, como la seguridad ante invasiones costeras y un mejor acceso a la capital ${ }^{114}$. El proyecto de crear la provincia de Valparaíso con las localidades de Quillota y Casablanca, en cambio, fue el que ofreció argumentos más sólidos, pues exhibió una serie de elementos reales que sustentaban su interés por erigirse en provincia independiente. Sus representantes presentaron consideraciones que iban desde lo estratégico y militar, hasta lo económico y burocráticoadministrativo ${ }^{115}$. A pesar de ello, el gobierno no aprobó su iniciativa, advirtiendo que "Valparaíso no tiene aptitudes de por sí, y defraudaría enormemente las de la provincia a que ha sido enumerado", además de que "pretendería erigirse en cabecera, y no es lo mas llano entre los políticos la creación de capitales litorales, expuestas a los riesgos de la invasión"116.

Todo lo contrario ocurrió con la solicitud de Talca de segregarse de la provincia de Colchagua y erigirse como capital provincial, la que se diferenció sustancialmente de las dos anteriores. La discusión fue constante durante 1826, se reavivó en los años siguientes y el carácter con que se manifestó ante las autoridades fue agresivo en ocasiones. Por ello fue la que mejor representó los intereses particulares provinciales, ya que nunca expuso razones concretas para sus pretensiones. Es más, solo recordó su tradición histórica de principal ciudad de la región y resaltó

114 SCL, tomo XII, sesión del 28 de agosto de 1826 y SCL, tomo XIII, sesión del 3 de noviembre de 1826.

115 El proyecto de ley se presentó el 31 de julio de 1826 y su iniciativa se rememoró en marzo de 1827, donde se subrayó el requerimiento bélico de la ciudad portuaria, la cercanía geográfica de Valparaíso con Santiago y el hecho de ser el principal puerto de Chile y un importante punto comercial y mercantil. Las tres localidades de Valparaíso, Quillota y Casablanca conformaban un arco geográfico que sus representantes encontraban a todas luces beneficioso. En SCL, tomo XII, sesiones del 31 de julio y 9 de agosto de 1826 y $S C L$, tomo XIV, sesión del 26 de marzo de 1827.

116 SCL, tomo XII, sesión del 9 de agosto de 1826. 
frecuentemente sus preocupaciones y molestias, aludiendo constantemente a que se sentía perjudicada, humillada y degradada con la nueva división político-administrativa $^{117}$.

Talca rehusaba pertenecer a la provincia de Colchagua y someterse a la autoridad de Curicó. Sus representantes afirmaron que poseía las condiciones para constituirse como una provincia aparte y que recibiría a los pueblos que quisieran incorporarse a ella, apoyándose en la libertad para elegir la jurisdicción a la cual pertenecer, pues sostener lo contrario era visto como una manifestación autoritaria que coartaba el derecho provincial. Las declaraciones punzantes de sus habitantes fueron evidentes cuando expresaron que

"Talca no puede mirar con indiferencia ese cuadro en que, a su pesar, hace el papel de humillado con la fuerza, y sin consideración a que nunca dio mérito a un envilecimiento civil de tanta trascendencia, cuando, por otra parte, no le faltaban motivos de prometerse mejor fortuna en lugar de la degradación a que la han reducido nuestros legisladores" 118 .

Sostuvieron también que su ciudad "está convencida que su dependencia de la villa de Curicó resiente lo más delicado de su honor, haciéndole retrogradar mil pasos de aquel esplendor que justamente se había adquirido"119. Frente a las demandas de los talquinos, el gobierno manifestó que

“después de ser sorprendida por el estilo punzante, poco decoro con que aquel pueblo provoca a la representación nacional, observa que la fuerza elemental de su reclamo consiste puramente en intereses de localidad y capitalismo. Talca se queja, humillada en la demarcación sancionada del territorio del Estado, y el Congreso, contraído por su propia naturaleza a formar provincias respetables, no pudo contraerse a fomentar el amor propio de esta ciudad" 120 .

Los intereses locales se manifestaron de forma concreta en el tema de las capitales provinciales y en las peticiones de los cambios de jurisdicción. En un escenario en que las aspiraciones principales se relacionaban con una mayor autonomía provincial y mayores libertades regionales, predominó la idea de que las unidades político-administrativas podían disponer libremente de aquellas decisiones que les afectara de forma directa, como las relativas a la división de la república. Esta realidad contribuyó en gran medida a la repercusión que tuvieron los intereses locales en el proceso de formación de la primera división, y explica que tardara años en materializarse. Los constantes debates entre los poderes del Estado, la rivalidad entre las provincias y las disconformidades de algunas ciudades con los

117 En $S C L$, tomo XII, sesión del 9 de agosto de 1826; SCL, tomo XIII, sesiones del 3, 16, 20 y 31 de octubre de 1826; SCL, tomo XV, sesión del 16 de julio de 1827 y SCL, tomo XIV, sesión del 11 de junio de 1828 .

118 SCL, tomo XIII, sesión del 3 de octubre de 1826.

119 SCL, tomo XIII, sesión del 16 de octubre de 1826

120 SCL, tomo XIII, sesión del 20 de octubre de 1826 
planes de demarcación, impidieron que existiera una organización estable del territorio durante el período analizado.

Además, nada explica mejor la presencia del localismo y su influencia en la dilación del primer ordenamiento político-administrativo, que la tergiversación que realizaron los dirigentes nacionales del sistema federal, lo que se vio claramente en sus disposiciones legales, donde continuamente facultaban a las asambleas provinciales para cambiar sus capitales y demarcaciones jurisdiccionales según la conveniencia y común acuerdo de las partes involucradas, creyendo, quizás ingenuamente, que se llegaría a un entendimiento mutuo. En los casos en que no se resolvía el problema, los representantes provinciales acudían a las autoridades nacionales para que estas intervinieran. Cuando estas intercedían, eran ignoradas por los afectados si la resolución no era de su conveniencia, argumentando constantemente que los pueblos poseían el derecho de velar por sus intereses, como ocurrió en los casos más críticos, como el de Talca. Las ciudades que solicitaron erigirse como cabeceras, o plantearon cambios de jurisdicción, se apropiaron de aquellas facultades, aunque ignoraron el procedimiento establecido para ejercerlas, lo que muestra el absoluto desorden con que se realizaban las peticiones. Muestra a su vez del estado institucional del país en la época. 